\title{
Apollonius Dyscolus and the Ambiguity of Ambiguity
}

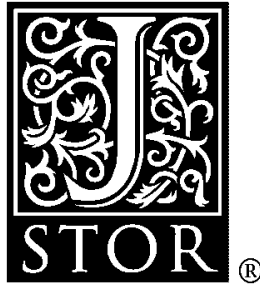

\author{
Catherine Atherton
}

The Classical Quarterly, New Series, Vol. 45, No. 2. (1995), pp. 441-473.

Stable URL:

http://links.jstor.org/sici?sici=0009-8388\%281995\%292\%3A45\%3A2\%3C441\%3AADATAO\%3E2.0.CO\%3B2-T

The Classical Quarterly is currently published by The Classical Association.

Your use of the JSTOR archive indicates your acceptance of JSTOR's Terms and Conditions of Use, available at

http://www.jstor.org/about/terms.html. JSTOR's Terms and Conditions of Use provides, in part, that unless you have obtained prior permission, you may not download an entire issue of a journal or multiple copies of articles, and you may use content in the JSTOR archive only for your personal, non-commercial use.

Please contact the publisher regarding any further use of this work. Publisher contact information may be obtained at http://www.jstor.org/journals/classical.html.

Each copy of any part of a JSTOR transmission must contain the same copyright notice that appears on the screen or printed page of such transmission.

JSTOR is an independent not-for-profit organization dedicated to and preserving a digital archive of scholarly journals. For more information regarding JSTOR, please contact support@jstor.org. 


\section{APOLLONIUS DYSCOLUS AND THE AMBIGUITY OF AMBIGUITY}

I

Apollonius Dyscolus' use of ambiguity in grammatical problem-solving has in recent years had the benefit of two scholarly studies. David Blank, in the course of his analysis of the Syntax as a whole (1982), has described the broad functions which Apollonius assigns to ambiguity. Jean Lallot's 1988 paper, 'Apollonius Dyscole et l'ambiguïte linguistique: problèmes et solutions', is devoted exclusively to the treatment of linguistic ambiguity in Apollonius' work. Yet it is to be feared that the flood of light thrown by these scholars on what had been an unregarded corner of ancient grammar has shown up rather more than Apollonius would have cared to admit, both about the nature, and about the prospects for success, of the enterprise on which he was engaged. At the same time, certain structural features of ancient grammar, at least of the ancient grammar which Apollonius himself constructed, have come into sharper focus: features clear enough with the benefit of hindsight, but glimpsed, it appears, all too dimly by Apollonius himslf. It is now worryingly clear not only that ambiguity was ambiguous for Apollonius, but also that the ambiguity of ambiguity represented a genuine threat to the coherence and value of his work. In this paper I set out to justify both these claims.

\section{II}

It hardly needs be said that ancient Greek, like, it seems, all natural languages, contains many instances of what Apollonius calls variously $a \dot{\mu} \phi_{\iota} \beta_{\circ} \lambda \lambda_{\imath} a$, 'ambiguity', $\sigma v^{\prime} \gamma \chi v \sigma \iota s$, 'confusion', $\sigma v \nu \epsilon ́ \mu \pi \tau \omega \sigma \iota s$, 'coincidence', $\sigma v ́ \nu o \delta o s$, 'congruence', or simply ó $о \phi \omega v i ́ a$, 'homophony'. In such cases - to use a modern jargon-different lexemes share a form or forms, or the same lexeme has different morphosyntactic words sharing or realised by the same form ('syncretism'). Coincidence can occur in any respect formal differentiation of which is characteristic of the part of speech in question: case, gender, person, number, voice, mood, tense, and so on (cf. synt. III 27 , p. 292.17f.1) $;^{1}$ and it can occur at the syntactic level as well. For example, in the word or word-form '́ $\mu o \hat{v}$, there is not only coincidence of the genitive case of two words or lexemes, '́ $\gamma \omega^{\prime}$ 'I' and '́ $\mu o^{\prime}$ ' mine', but also an overlap between the sorts of construction into which these two (morphosyntactic) words can enter (synt. II 117, p. $216.8 \mathrm{ff}$., III 48, p. $314.1 \mathrm{ff}$; pron. $64.25 \mathrm{ff}$; ; and cf. synt. III 49, p. $314.3 \mathrm{ff}$., on $\dot{\epsilon} \mu \mathrm{\imath}$ ) . Again, some nouns may have homophonous nominative and vocative, or nominative and accusative cases; and the former type of ambiguity or homophony can co-occur with homophony of the indicative and imperative moods of certain verbs to create ambiguity in word sequences (synt. I 48, p. 41.18, III 53, p. 318.6f., III 118, p. 371.5ff.). Formal coincidence has also, for example, produced two adverbs, iva and o' $\phi \rho$, equivalent respectively to 'when' and 'until', which look and sound identical to two conjunctions, both equivalent to 'so that' (coni. 214.12-17). And Apollonius criticises the Stoics for overlooking what he calls the óoфwvía of articles and

${ }^{1}$ All references to Apollonius' works will be to the Grammatici Graeci (G.G.) edition: see bibliography for details. 
pronouns when they argued that these belong to a single part of speech (pron. 7.20, cf. 8.22). ${ }^{2}$

Apollonius was not, of course, the first theorist to observe the phenomenon of ambiguity: the novelty lies in the uses to which he put it. David Blank has pointed out two such uses in the field of syntax $(1982,36 \mathrm{f}$.). First, ambiguity functions as a sort of camouflage for the congruity of constructions, 'congruity', $\dot{\eta} \kappa a \tau a \lambda \lambda \eta \lambda \hat{o}^{\prime} \tau \boldsymbol{s}$, $\tau \dot{o} \kappa \alpha \tau \alpha \dot{ } \alpha \lambda \eta \lambda o \nu$, being the guiding principle of language in Apollonius' theory of language and his methodology (1982, 11ff., 21ff.). ${ }^{3}$ Constructions apparently incongruous turn out not to be when it is seen that one or more words in them are

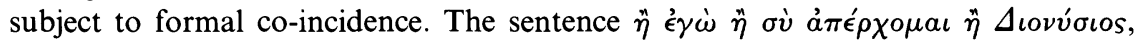
'either I am leaving or you $\langle$ are $\rangle$ or Dionysius $\langle$ is $\rangle$ ', for instance, will be incongruous if $\sigma v^{\prime}$ 'you' is taken to be in the vocative case, which is what Apollonius' opponent here maintains; if, however, $\sigma \dot{v}$ is in the nominative, as $\epsilon^{\prime} \gamma \omega^{\prime}$ and $\Delta \iota v^{\prime} \sigma \iota$ 'os are, it will not (synt. III 39, p. 305.7ff.; cf. Itkonen [1991], 211). Second, avoidance of ambiguity helps explain 'many systematical rules of syntax' (Blank [1982], 37). To take another of Blank's own examples, the masculine singular definite article $\delta$ originally had the form ${ }^{*} \tau o s$, but lost its initial $\tau$, and then its final $s$, to avoid confusion with the relative pronoun os; in this way the appearance of incongruity is avoided (synt. I 80, p. 68.2ff.). Genuine incongruity would not occur, because the syntactical rôles of $\delta$ ' the' and ös 'who' are quite different." Blank does not comment explicitly on one important consequence of language's tendency to avoid formal coincidence: the resulting deviations from regularity at the level of inflection. This point will come up for us again later.

Whereas Blank focusses on the explanatory functions of ambiguity in Apollonian syntax, Lallot sets himself the tasks of examining Apollonius' vocabulary for the description of cases of ambiguity $(1988,34-7)$, of classifying the cases of it which Apollonius mentions or discusses (37-40), and of analysing the techniques of disambiguation he employs (40-46). A thought-provoking assessment of the place of ambiguity in Apollonius' theory of language and methodology rounds off Lallot's paper (46-9). But neither these concluding general reflections, nor the classification of ambiguity types, with its broad dichotomy into lexical and grammatical ambiguity and its numerous subdivisions, nor the classification of disambiguation techniques, have any basis in originals supplied by Apollonius himself, as Lallot himself warns us (34 and n. 3).

Indeed, Apollonius fails to offer explicitly so much as a rough definition, or, with one or two limited exceptions, the broadest of categories for the items he treats as cases of ambiguity, homophony, formal co-incidence, and so on. His preferred terminology points to a comparable indifference, as we shall see. Why, though, does Apollonius omit to define or classify ambiguity? And are these omissions important

2 On this portion of Stoic grammatical theory: D.T. Sch. 519.12ff., and cf. Frede (1978), 66; Atherton (1993), 301, 306f., 369 n. 130; on Apollonius' criticisms of it: Sluiter (1990), 124.

${ }^{3}$ My earlier claim (Atherton 1993, 490) that ambiguity for Apollonius is mainly 'a limitation

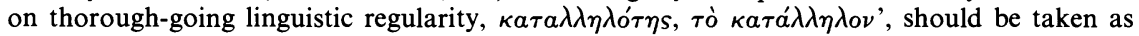
referring both to the actual restriction effected by ambiguity on grammatical congruity (which occasionally loses out to formal co-incidence), and to the apparent restriction of grammatical congruity by forms which turn out to be coincident. Deviation from formal regularity is another effect of ambiguity. All these aspects of ambiguity's impact on language will be dealt with in the main text.

4 For Apollonius, and ancient grammarians in general, the relative pronoun is not a pronoun

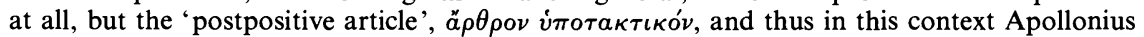
distinguishes not between articular and pronominal syntax, but between prepositive and postpositive articular syntax: synt. I 80, p. 68.1. 
ones? I shall offer both an explanation of his silence, and an argument that his silence is significant; and the second of the two questions just posed will lead us back to the ambiguity of ambiguity for Apollonius: on the one hand, ambiguity both confirms and challenges his claims to be a rationalist grammarian; on the other, it threatens his status as a technical grammarian, while demanding the sort of treatment which only a technical grammarian-or a linguist?-could give it.

\section{I}

It is, I think, worth bearing in mind what a powerful and yet delicate instrument of torture ambiguity can prove on recalcitrant theories and arguments. Hidden assumptions about what is, and is not, linguistic, or about what is, and is not, linguistically important, and why, are readily confessed under its ministrations. Satisfactory responses to the phenomenon of ambiguity presuppose or involve satisfactory answers to many, if not all, of those questions which are at once awkward, and crucial to the broad range of theorizing about language, about language knowledge, and about the proper methods and goals of studying language or languages. To understand ambiguity we must understand, for example, what sorts of thing are to count as linguistic items at all; how they have meaning; how numerically different items can count as relevantly 'the same'; how these tokens and their types can have meaning in such a way that they can have more than one meaning, and can be intuitively recognised and described as such; which criteria are appropriate for judging a candidate ambiguity; how ambiguity differs from, inter alia, generality, vagueness, and multiple reference; what rôles context, situation of utterance, and other factors play in both creating and defusing ambiguity; how all these problems affect our conceptions of the objects and internal relations of the linguistic sciences; and so on.

Now, as we shall see, Apollonius requires a certain amount of encouragement to reveal his solutions even to the problems which can be properly expected to interest him most. On some of them he is completely silent: and to expect otherwise would be hopelessly anachronistic, for Apollonius is engaged on an enterprise of his own devising, and not on a prototype of some one or other of the modern variants of theoretical or applied linguistics. We cannot expect his problems, aims, and methods to be ours, or ours his. But assessment of Apollonius' success by his own lights is indeed acceptable and appropriate-necessary, rather, if we are to treat him with the respect he deserves: necessary too if we are looking to him for help, for inspiration, or even for salutary lessons. However alien, obscure, and remote his work may seem, we must both deal with it on its own terms, and seek out appropriate comparisons and contexts for it, ancient and modern alike, whether in technical grammar or linguistics, in literary or textual criticism, in philosophical logic, in the philosophy of language, or in any of the disciplines we have constructed to deal with language and languages.

My own conviction is that Apollonius' failure to attend to appropriate generalisations about ambiguity betrays a fundamental and ineradicable difference between ancient and modern conceptions of what grammar is, and of its purpose. The significance of Apollonius' failure, together with its larger context, will, I hope, be clearer with the aid of a few contrasts between his work and the modern rôles and uses of ambiguity by modern linguists. The field is an enormous one (a significant fact in itself), and I shall focus on only three small but important areas of it.

Approaches to ambiguity typology in antiquity will seem to modern readers quite 
alien, in content and structure as much as in the contexts within which the classifications were drawn up, or in the purposes of the classifiers. In particular, no conscious attempt seems ever to have been made to construct exhaustive typologies, whether for Greek or for Latin, of the ambiguities made possible by the phonological, morphological, or syntactic characteristics of the language. ${ }^{5}$ Yet this is a fairly common, and certainly widely acceptable, approach to ambiguity today. ${ }^{6}$ It is not that ancient classifiers of ambiguity were insensitive to the potential of these characteristics for creating ambiguities. The ambiguity was recognised, to cite one, tiny example, of forms common to the deponent and passive in Latin, as with criminor, 'I accuse'/'I am accused', and this was given a special name, ambiguity per communia verba. ${ }^{7}$ Such grammatical analyses may be implicit in the lists of disambiguation techniques very often appended to the classifications proper. Quintilian (inst. rh. VII ix 9, with ix 6f.) thus suggests change of grammatical cases for remedying ambiguities of the double-accusative-plus-infinitive type, such as that notorious Pythian oracle, delivered to Pyrrhus and repeated ad nauseam by ancient classifiers, 'aio te, Aeacida, Romanos vincere posse' ('I tell you, son of Aeacus, you the Romans can defeat', Ennius VI 186 Vahl). Such disambiguation procedures may themselves contribute to an author's classificatory principles, as seems to be the case with Quintilian's own list. ${ }^{9}$ But no systematic classification of ambiguities by reference to such features has survived. The fact, then, that Appollonius also deals only in piece-meal fashion with ambiguity considered as a product of the peculiar sound-patterns, orthography, inflections, or constructions of Greek, is not surprising in itself: it becomes so only when we come to reconstruct and assess his own theory and methodology of grammar. The same will be seen to hold of what we would regard as errors in his implicit classification of ambiguity types.

Another important point of contrast between ancient and modern treatments of ambiguity is that there seems to have been no ancient counterpart to the selfconscious and formal acknowledgement of ambiguity's heuristic and explanatory functions within modern general linguistics. Two such heuristic functions stand out in the recent past of the discipline, and I shall describe them briefly.

${ }^{5}$ Classifications and definitions of ambiguity in grammatical treatises, for example, can almost always be found in the sections dealing with stylistic defects, of which inclarity was one cause, ambiguity being in turn a cause of inclarity. Rhetoricians too treat it as a stylistic defect, and also as a source of legal dispute. There are examples of both approaches in Quintilian inst. rhet. VII ix, VIII ii 16. (Occasionally, ambiguity will be raised to the status of a stylistic ornament: e.g. ad Her. IV 67.) For a general discussion: Atherton (1993), 24-27; also 473-82 (stasis theory); 483-6 (stylistics). As for Aristotle's famous and influential classification of ambiguity types in his Sophistical Refutations (s. el.) $2166 \mathrm{a} 24 \mathrm{ff}$.), this is actually a classification of types of fallacy due to language, comparable to the collection of apparent enthymemes due to language in the Rhetoric (rh.) (II 24 1401alff.); the list of genuine ambiguity types in the Poetics (25 1461a21ff.) is very brief and vague. Only two Stoic ambiguity classifications have survived, and these appear to be more or less context-neutral (although one has a more stylistic flavour), with certainly no suggestion that classification of lexical or grammatical categories open to ambiguity was intended, even if the lists constituted convenient vehicles for instruction in (inter alia) Stoic grammar (cf. Atherton [1993], 215-20, 406).

6 So e.g. Hirst (1987), 149 (English); Chao (1959/60), 3ff. (modern Chinese).

7 Aulus Gellius noct. att. XV 13; Diomedes ars gr. (G. L. I) 450.10-12; cf. Charisius inst. gr. (G.L. I) 271.27; Anecdota Helvetica (G.L. suppl.) XLVI.31f.; and cf. Desbordes (1988), 88f., who points out that such verbs are said to have a double 'significatio', this being the technical term for 'voice'.

${ }^{8}$ E.g. Diomedes 450.3; Charisius 271.28; Anecdota Helvetica cod. Bern. 16, p. XLVI.27. Oracles became notorious for exploitation of ambiguity: Aristotle $r h$. III 5 1407a37-9; Plutarch orac. Delph. 26 406F-407A; Ammonius int. 137.12ff.

${ }^{9}$ See Atherton (1993), 478-80. 
First, ambiguity has been argued to permit generalisations about properties of linguistic items which otherwise would go undetected and undescribed at a theoretical level; and this argument may be buttressed by further argument to the effect that ambiguity itself is one of the cardinal properties of sentences intuitively recognised by native speakers, alongside grammaticality, acceptability, meaningfulness, and synonymy, and as such requires description by the grammarian. This approach to ambiguity was common in, although by no means exclusive to, TransformationalGenerative grammar, which used its purported ability to explain ambiguities not explicable by its rivals as proof of its superiority. ${ }^{10}$

Second, the threat posed by ambiguity to semantic efficiency may be exploited to construct 'functional' explanations of Greenbergian linguistic universals-briefly, empirically-based generalisations about the properties of all languages, or about the relations between their properties. The presence of a property, or its regular association with, or dissociation from, another property, may be accounted for as contributing to the semantic efficiency of the language, and the 'functionality' of universals has been described as increasing 'the ease with which the semantic content of an utterance can be recovered from its syntactic structure' (Payne [1990], 304). Thus Keenan uses, inter alia, ambiguities in English $(1988,110)$ and Malaylam (116) to help in the application to natural languages of his 'semantic case theory', which aims to explain asymmetries between subjects and objects as regards quantifier scope, as well as the interpretation of anaphors. ${ }^{11}$ More directly, appeal has been made to the avoidance of ambiguity to explain the use of different cases to mark subject and object in transitive constructions $;^{12}$ and it is thus striking that in Apollonius we find an argument that the order of accusative case nominals in oratio obliqua indicates the correct structure, and thus the meaning, of the whole construction, with the 'agent' ('ं $\nu \epsilon \rho \gamma o v i v)$ preceding the infinitive verb, the 'patient'

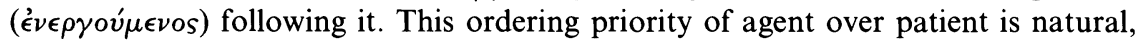
and any alteration in it constitutes an instance of the figure hyperbaton, 'transposition'. This implies that the formal differentiation of cases in oratio recta has syntactic and semantic functions, which are taken over entirely by ('natural') position in oratio obliqua (synt. III $84-7$, pp. $344.1 \mathrm{ff}.){ }^{13}$

10 Thus Kooij $(1971,62)$ could claim that 'It is no exaggeration to state, that in general the degree to which a grammatical description is capable of recognizing that otherwise identical sequences of linguistic elements are homonymous and should be assigned to more than one grammatical structure, has become one of the major tests for the adequacy of such a description, and also, that this is largely due to the impact of Transformational grammar'. For an enlightening account of the changing theoretical and methodological status of ambiguities, and of native speaker intuitions, including ones about ambiguities, in Chomsky's earlier thought, see Matthews (1993), 139f., 168f., 173ff., 193-205, 245f. (This discussion of the exploitation of ambiguity in modern linguistics draws in part on Atherton [1993], 18-21, 494f.).

11 Note that one objection raised by Hawkins (1988b), 10 to this semantic project refers to syntactic 'rules creating ambiguities'; and Comrie (1981), 25 observes that '[m] any linguists are skeptical of functional explanations, pointing out, quite correctly, that there are numerous instances in which language seems to be dysfunctional. For instance,...the existence of homonyms would seem to create needless complications by having potential confusion through identical names for different concepts'.

12 See Anderson (1976), Comrie (1978). Other examples of the explanation of particular linguistic phenomena as ways of avoiding ambiguity can be found in Mallinson and Blake (1981), 322ff., 341ff., 366f., Comrie (1988), 192, 199-203.

${ }_{13}$ This rule is for us highly dubious. (On the 'ontological' basis for it: Itkonen [1991], 213.) I shall not attempt, in this paper, to review or assess all the rules of syntax which Apollonius applies in cases of ambiguity. My purpose is rather to analyse his deployment of these rules as a defence against ambiguity, than to test their acceptability as rules of syntax. 
Now this example, significantly, is singled out for attention by Lallot $(1988,48)$ as showing the limits of Apollonius' interest in ambiguity: Apollonius precisely does not

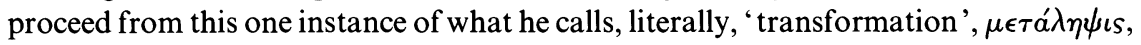
to construct a theory of transformation. He does use the technique of transformation, apparently borrowed from Stoic doctrine and then, probably, expanded and adapted, quite freely elsewhere $;^{14}$ but no explicit general account of its survives, and this text is one more example of that general failure. Of immediate concern to us, rather, is another omission signalled by this text: there is not so much as a glance at the ways in which such case ambiguities might be classified. That Apollonius argues against the ambiguity of the sort of sentence in question is irrelevant. He could still have noted the place such putative ambiguities typically found in earlier and contemporary codifications of ambiguity types had he thought it important to do so. The case in question is of particular interest because, as Lallot observes $(1988,39)$, it follows automatically on the application of the rules of the infinitive construction: some syntactic ambiguity is thus inherent in-or rather, according to Apollonius, appears to be inherent in - the structure of ancient Greek.

Proof that such classifications of multiple case ambiguities were available is easy to find. Quintilian's reference to them, and description of the correct way of eliminating them, have already been noted (VII ix 7, VIII ii 16). A passage from the rhetorician Theon of Alexandria, who probably lived before Apollonius, but may have been a contemporary of his, confirms knowledge of them in the Greek tradition (progymnasmata II 82.32-83.12 Sp.). ${ }^{15}$ There are any number of similar cases of oratio obliqua ambiguity in the rhetoricians and grammarians. ${ }^{16}$ The crucial point is that Apollonius does not mention any such classificatory resources; and it is surely significant that none of Apollonius' now lost works was, it seems, devoted to ambiguity per se, as Lallot reminds us (1988, 34 n. 2).

\section{IV}

Of the only two distinctions Apollonius does appear to have made in the field of ambiguity, one was between homonymy and all other types of multiple signifying, the other, within the latter category, between grouping ambiguities and all others. It is Apollonius' vocabulary which must be our guide here, for, as already noted, nothing explicitly designated as a definition or classification is on offer. Lallot's otherwise

14 For the Stoic theory of inflection or transformation of propositions: Alexander an. pr. 403.14ff., Sextus $M$. X 99f.; for another survival of it, Simplicius cats. 406.13f.; and cf. Lloyd

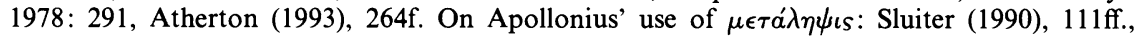
Itkonen (1991), 207-201. I would certainly not go so far as to agree that Apollonius has anything comparable to modern transformational theory, as suggested by Householder in the Introduction to his translation of the $\operatorname{Syntax}(1981,13 \mathrm{f} ., 16)$ and apparently accepted by Itkonen (1991), 210; cf. Sluiter (1990), 65-7.

15 Here Theon is, I believe, misinterpreting a Stoic ambiguity kind as embracing a subdivision of what was originally an Aristotelian ambiguity type: the subtype classifies ambiguities caused by absence of formal differentiation, by way of grammatical case, of different grammatical

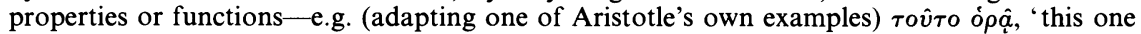
sees' (cf. s. el. 4 166a10). This point of interpretation (on which see Atherton [1993], 390-97) is in the event irrelevant, except as confirming the availability of a variety of classificatory pigeonholes for such ambiguities. On Theon's date, see Lana (1951), 108-51 (on the relation between Quintilian's institutio rhetorica and Theon's progymnasmata); Butts (1986), 2-6; Atherton (1993), 184.

16 E.g. Charisius (G.L. I) $271.27 \mathrm{ff}$. (where this is the only example of ambiguity in a sententia); Diomedes (G.L. I) 450.1-7 (similar); Anec. Helv. XLVI.23f. (ambiguity 'per casum accusativum'); Trypho III 204.2 Sp.; Cocondrius III 243.13, $15 \mathrm{Sp}$. 
useful account of Apollonius' vocabulary in the field $(1988,35 \mathrm{f}$.) is restricted to $\dot{a} \mu \phi \imath \beta o \lambda i ́ a, a \dot{\alpha} \mu \phi i \beta o \lambda o s$, and kindred terms, neglecting other items in what we shall see was a varied and lengthy list. The fluidity of Apollonius' categories can best be appreciated by tracing the terminology he himself employs to describe the cases of ambiguity exhibited in Lallot's classification of Apollonian ambiguities (with the addition of a few further instances where necessary). Such a comparison will make perfectly clear the gap which divides Lallot's precise and persuasive categorisation from the Apollonian reality - and that despite the former's deliberate concessions to flexibility and duplication.

Homonymy, $\delta \mu \omega \nu v \mu i a$ (Lallot [1988], 37), seems to be restricted to proper names (synt. I 65, p. 56.6f., 121, p. 102.10f.), such as 'Ajax' (I 65, p. 57.1f.; 121, p. 102.11, 15 ; pron. 4.11, 12f., 10.12) and 'Ptolemy' (synt. I 40, p. 115.4). Synt. I 65, p. 56.6-8 reports that 'in proper names homonymy is a problem; the ambiguity [ $\tau \dot{o} \alpha \dot{\alpha} \mu \phi i \beta o \lambda o v]$ arising from it is not resolved without addition of an epithet to the proper names'. Homonymy, then, causes ambiguity. ${ }^{17}$

(This should not, incidentally, be thought an innovation or eccentricity on Apollonius' part. Proper names shared by several bearers were in fact the examples imprimis of ambiguity in single terms, Homer, presumably, being the unimpeachable authority in this matter [Il. 17.720, the two Ajaxes; cf. e.g. Ebbesen, 1988, 27f.]. It was common too to cite not only proper names as examples, but also words or forms which could function as both proper names and general terms, such as 'taurus', 'gallus', 'phoenix', or $\kappa v ́ \omega \nu.)^{18}$

Homophony, ó $\mu \circ \phi \omega \nu i a$, occurs, according to Lallot $(1988,37 \mathrm{f}$.) by $\sigma v \nu \epsilon ́ \mu \pi \tau \omega \sigma \iota s$ of two or more words of 'syntagmes'. His example is from pron. 52.5, and the relevant passage is worth quoting in full:

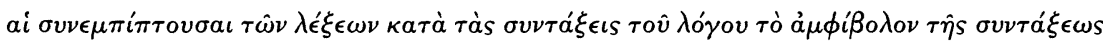

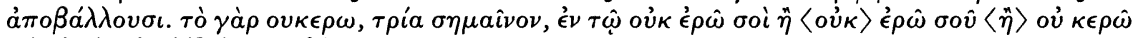

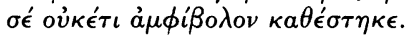

Such words as formally coincide lose their syntactic ambiguity thanks to sentential

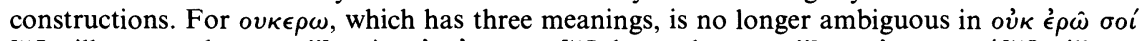
["I will not speak to you"] or in oủk é $\rho \hat{\omega} \sigma o v$ ["I do not love you"] or ov̉ $\kappa \epsilon \rho \hat{\omega} \sigma \epsilon ́$ ["I will not trim your hair"].

(pron. 52.4-7)

This is an important and illuminating text for our purposes. There is, first, no mention of homophony by name, although Apollonius elsewhere freely uses both o $\mu \circ \phi \omega \nu i a$ and the related adjective/substantive $\dot{\alpha}$ ó $_{\phi} \omega \nu$ os $/ \nu$ (to which I shall shortly return). Any ambiguity belongs instead to 'coincident' $\lambda \epsilon^{\prime} \xi \epsilon \iota S$ (52.4). Now $\lambda \epsilon^{\prime} \xi \iota s$ is usually Apollonius' term for 'word ', ${ }^{19}$ and two of the meanings of the ambiguity in question

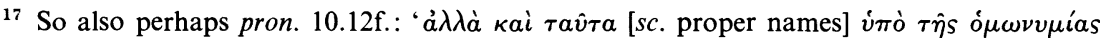

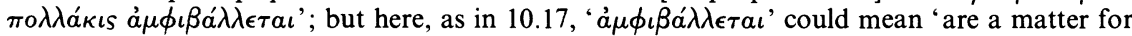
dispute', because they fail to 'determine', 'ó $\rho \zeta \epsilon$ '. 10.11, who is being referred to. There is a fine line between being doubtful and being ambiguous, as Lallot (1988), 36f. properly observes. At pron. 105.31, $\delta \mu \omega \nu v \mu \epsilon \hat{\imath \nu}$ must mean 'be the equivalent of' or 'have the same meaning as' in another dialect (as Doric $\tau \epsilon o ́ s$ is the equivalent of Attic $\sigma o ́ s)$. These two passages thus at least help confirm the looseness of Apollonius' terminology.

18 'Taurus': Diomedes 450.8 (and see p. 449 and n. 27); 'gallus': Quintilian VII ix 2; 'phoenix': D.T. Sch. 389.4f.; $\kappa \dot{w} \omega v$ : D.T. Sch. 389.5, Simplicius cats. 26.24f. Some sources classify homonyms explicitly as common or proper: D.T. 36.2f.; D.T. Sch. 389.7-10 (where it is apparently not noticed that '(the) Dog' (i.e. 'the Dog Star', = Sirius) is a proper name).

19 At e.g. synt. II 56 , p. 169.6 , III 128 , p. 380.7 , 'lexeme' seems closest to Apollonius' meaning, but at e.g. adv. 147.5-7, 163.17, pron. 34.21 , synt. I 75 , p. 64.1 , I 76, p. 65.4, 'form' looks more appropriate (for which $\phi \omega \nu \eta$ ' seems sometimes to be used; cf. II 117, p. 217.2f.). But it would be both anachronistic, and insensitive to the fluidity of Apollonius' terminology, to take 
could be described as lexical, in a broad sense: $\epsilon$ $\rho \hat{\omega}$ can mean 'I will speak' or 'I love', the ambiguity being removed, as Apollonius shows, by addition of an oblique case (dative or genitive respectively). But the third meaning cannot be so classed; rather, the sequence $о v \kappa \epsilon \rho \omega$ (which could be a sequence of sounds or of letters, no distinction is made here $)^{20}$ is being differently divided or analysed, and we would, I think, want to say instead that morphological analysis has produced a new word-sequence, one different from oúk $\dot{\epsilon} \rho \hat{\omega}, v i z$, ov่ $\kappa \epsilon \rho \hat{\omega}$ 'I will not trim'. We may agree with the general point being made, that context can disambiguate, while remaining unconvinced that what happens when $о v \kappa \epsilon \rho \omega$ is contextualised is consistently disambiguation proper; or, to put it another way, that we are dealing with meanings of one and the same word or word-complex in all three cases. One two word-sequence (oủ $\dot{\epsilon} \rho \hat{\omega}$ ) has two meanings, another two word-sequence, oì $\kappa \epsilon \rho \hat{\omega}$, only one-and this, presumably, sounded the same as or very like ov่ $\dot{\epsilon}^{\prime} \rho \hat{\omega},{ }^{21}$ and was written the same as it in scriptura continua (still standard in Apollonius' day). ${ }^{22}$ We would have good grounds, then, for disagreeing with Apollonius that $о v \kappa \epsilon \rho \omega$ is ambiguous in all the ways he assumes. We should note too that neither here nor elsewhere does Apollonius make differences in the grammatical accidentia (which he would call their $\pi \alpha \rho \epsilon ́ \pi \sigma \mu \epsilon \nu a$, and which seem to be regarded as semantic or quasi-semantic (Sluiter [1990], 50f.; Ebbesen [1988], 30)) of items sharing an ambiguous form a principle of classification of ambiguities: here, for example, the fact that one of the two verbs signified by $\epsilon \rho \hat{\omega}$ is present tense and

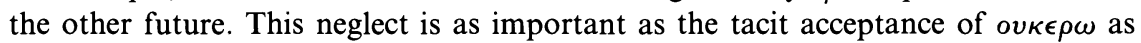
ambiguous in three and not just two ways.

Some light may be thrown on that assumption by further examining the term $\lambda \epsilon^{\prime} \xi$ เs. This, as noted, typically means 'word' for Apollonius. But for the Stoics it did not:

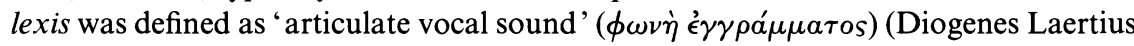
VII 56), a definition motivated not only by recognition of the existence of articulate but meaningless utterances or inscriptions ${ }^{23}$ (VII 57), but also by the need to accommodate items taken to be ambiguous which were neither words nor sequences of these. Ambiguity, for the Stoa, is always lexis of such-and-such a sort (VII 62). Each of the two surviving Stoic ambiguity classifications ${ }^{24}$ contains a version of the solitary example preserved by Diogenes Laertius in his account of Stoic dialectic (VII the 'coincident lexeis' at pron. 52.4 as what we would call identical forms (of different lexemes, of different morphosyntactic words belonging to the same lexeme), or as the lexemes or morphosyntactic words themselves, rather than as somehow combining the two, or as implying a quite different classification. This indeterminacy in metalinguistic terminology is, however, standard throughout all Apollonius' discussions of or allusions to ambiguity, and I shall not pursue the general point further here. A $\lambda \epsilon^{\prime} \xi_{\text {is }}$ can also be a phrase or word-sequence (synt. IV

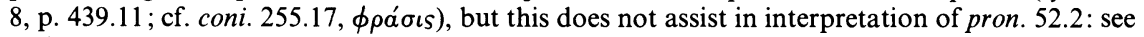
main text. (Schneider's index to Apollonius (G.G. II iii 3) also lists 'sensus (Sinn)' as a possible meaning of $\lambda^{\prime} \xi_{\text {is }}$, but each of the three passages listed (synt. IV 23, p. 455.5, pron. 71.2, adv. $160.2)$ clearly requires 'word' instead.) 33.

${ }^{20}$ Some ambiguities are cleared up by prosody, pronunciation or punctuation: see further, $\mathrm{n}$.

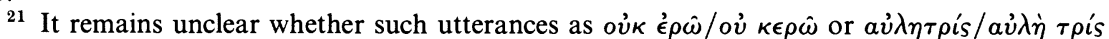
would have been automatically distinguished in speech: see n. 33, and also Ebbesen (1988): 23, Atherton (1993), 370 with n. 131.

${ }^{22}$ For roughly contemporary confirmation of this fact, see Galen de sophismatis in dictione (soph.) (C. Gabler [ed.], Rostock, [1903], (G); S. Ebbesen [ed.], Commentators and Commentaries on Aristotle's 'Sophistici Elenchi', [Leiden, 1981; 3 vols.] vol. II, pp. 1ff. [E]), p. 25 E, = pp. 15.9-16.1 G; and cf. Ebbesen (1988), 16, 25.

${ }^{23}$ Note that for the Stoics letters, $\gamma \rho \alpha \mu_{\mu} \mu \alpha \tau a$, are primarily, but not exclusively, speechsounds: D.L. VII 56.

${ }^{24}$ See Galen soph. c. IV, pp. 21-3 E, pp. 12.10-14.5 G, Theon prog. II 81.31-83.13 Sp. (There is a full discussion of these classifications in Atherton [1993], 175ff.) 
62 ), and this shows what was intended: the sound- or letter-sequence $\alpha v \lambda \eta \tau \rho \iota$ can be divided as $a \dot{u} \lambda \dot{\eta} \tau \rho i^{\prime}$, meaning 'a court three times', or form a single word, $a \dot{v} \lambda \eta \tau \rho i s$, meaning 'flutegirl'. ${ }^{25}$

Now this is not, admittedly, precisely the sort of ambiguity -if that is what it is - at

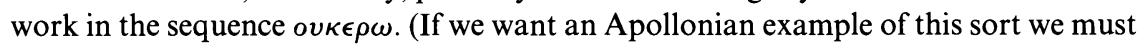
look elsewhere - in fact, to one of the cases classed by Lallot as syntactic, as we shall see a little later.) Exact parallels for ovкє $\omega \omega$ are to be found instead in the examples of another Stoic ambiguity species, that classifying invariant lexeis-letter-sounds or sequences of these-which can be variously combined to form different wordsequences. ${ }^{26}$ One of the Stoic cases is remarkably close: the lexis (= articulate

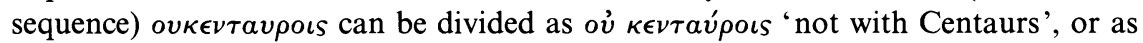

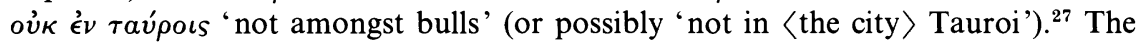

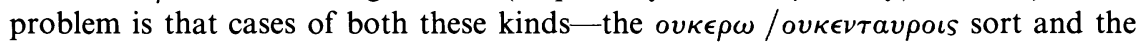
$a v \lambda \eta \tau \rho \iota s$ sort-are not obviously genuine ambiguities, that is, authentic linguistic items which might actually constitute an utterance of a competent speaker, and which happen to have two or more meanings. Mere strings of sounds or letters corresponding, more or less closely, at the spoken and/or written level, to a number of words or word-sequences, each of which is univocal, are not utterances of this sort. ${ }^{28}$ But this - to us potent-objection seems never to have been raised in antiquity, and Apollonius was not alone in following the Stoic lead. ${ }^{29}$ The passage quoted earlier, about the effects of context on ambiguities, is thus a warning not to expect Apollonius' ideas about what does or does not count as an ambiguity to match our own. And we must already be less inclined to take Apollonius' failure to use classifications as merely a sign of dissatisfaction with what was available to him.

So, if $o v \kappa \epsilon \rho \omega$ is not (labelled) an instance of homophony, what is? And how is homophony connected with $\sigma v \nu \epsilon^{\mu} \mu \tau \omega \sigma \iota s$, 'formal coincidence'? Lallot mentions coincidence of forms again a little later, as a cause of ambiguity 'par déficience de la morphologie' (1988, 38: the second category of ambiguity); it can occur 'par la flexion' (say, identity of forms in the indicative and imperative moods), and 'par la dérivation' $(1988,39)$ (as with '́ $\mu o \hat{v}$, the example already described). It will probably come as no surprise that Apollonius' own descriptions support neither this dichotomy nor a distinction, also observed by Lallot $(1988,38)$, between such instances and ones where there is 'une indifférenciation de base' (as where different masculine and feminine forms of an adjective do not exist). The same holds for Lallot's first category of grammatical ambiguity, 'par l'indétermination (aoristia)', the chief example of which is the personal pronoun $o^{30}$ and the possessive pronoun os derived from it (e.g. synt. II 108ff., pp. 209.10ff.). Lallot claims that is merely 'la version pronominale de l'homonumia lexicale', but, given Apollonius' restriction of homonymy to proper names, this is, as it stands, implausible. ${ }^{31}$

\footnotetext{
${ }^{25}$ Galen soph. pp. 21f. E, p. 13.1-3 G; Theon prog. 81.32-82.3.

${ }^{26}$ Galen soph. p. 22f. E, p. $13.16 \mathrm{G}$, Theon prog. 82.3-7.

27 Theon prog. 82.5. See also n. 18, on 'taurus'. $22 \mathrm{f}$

28 For a full discussion of this point: Atherton (1993), 243-50, 368; see also Ebbesen (1988),

${ }^{29}$ The 'multiple division' type of ambiguity or linguistic confusion is extremely rare in classifications, but seems to have caused textual and literary critics-understandably, given the usual dearth of diacritical and prosodic signs in ancient texts - a fair number of headaches (e.g. D.T. Sch. 444.22ff.). The 'single word/word sequence' type, significantly, tends to crop up in classifications amongst single term ambiguities (e.g. Quintilian VII ix 4).

${ }^{30}$ Lallot (1988), 38 has ' $h e$ ': I take this to be a typographical error for ' $h o$ '.

31 Equally unconvincing is Lallot's observation that this represents 'un cas particulier de l'indétermination inhérente à la troisième personne, indétermination maintes fois soulignée',
} 
Apollonius' vocabulary for formal coincidence reveals that no distinction was maintained between coincidence of forms of morphosyntatic words within a lexeme (syncretism), and coincidence of forms of different lexemes, and the fluidity of his terminology is indeed remarkable. Thus the adjective $\sigma \omega \phi \rho \omega \nu$, 'modest', suffers from

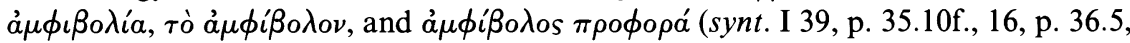

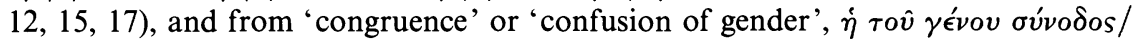
$\sigma v^{\prime} \gamma v \sigma \iota s$ (p. 35.12, p. 36.8), which must be made distinct (p. 35.6, p. 36.6, 13f.). The $2 \mathrm{P}$ plural imperative and indicative forms of some verbs are subject to homophony and ambiguity (III 103, p. 358.15, 16, III 120, p. 372.4f.). And yet '́ $\mu \circ \hat{v}$, which, as we saw earlier, is the genitive of two different words or lexemes, '́ $\gamma \omega^{\prime}$ 'I' and '́ $\mu o^{\prime}$ ' mine', and which is subject to coincidence in both form and syntactic rôle, is also associated with homophony and ambiguity (II 123, p. 221.7, III 48, p. 314.1; pron. 64.25f.). Likewise, ov , 'from/of him', the genitive of the 3P singular personal pronoun, is homophonous with the genitive of the 3P singular relative pronoun (pron. 75.26-76.1; and see in general synt. III 49, p. 314.12ff.). ${ }^{32}$

Clearly, then, Apollonius does not distinguish systematically even between intraand inter-lexemic coincidence. Still more remarkable is his treatment of what Lallot labels 'ambiguité syntaxique' $(1988,39)$. Again, I shall base my examination of Apollonius' vocabulary on Lallot's examples. Of these, the second is already familiar: the construction involving two accusative case forms and an infinitive. What Lallot does not observe is that Apollonius denies, implicitly, that such constructions are in fact ambiguous: as we saw earlier, it is precisely not true, in Apollonius' opinion, that 'ce type d'ambiguïté découle automatiquement de l'application des règles de construction de (ce que nous appelons) la proposition infinitive' (1988, 39). Admittedly, Apollonius opens his discussion with the assertion that 'ambiguities too arise from such constructions as these' (synt. III 85, p. 344.6), and he offers a solution of such cases $(86$, p. 344.13). But his claim of logical priority for agents over patients, and, on this basis, of syntactic (= ordering) priority for (nominals denoting) agents over (nominals denoting) patients (86f., p. 344.13ff., esp. p. 345.10-15) effectively eliminates any (ostensible) ambiguity from such constructions. Only then, at all events, could Apollonius claim that that notorious Homeric line ' $\delta$ òs $\delta \epsilon^{\prime} \tau$ ' ${ }^{\epsilon} \mu$ ' $a ̈ \nu \delta \rho \alpha$

which Apollonius, none the less, considers only in its species-proper names (see already p. 447), the reflexive/non-reflexive use of pronouns in Homer, as in the case of of and os - never in the general (1988: 38). Lallot refers too to 'l'ambiguïté inhérente à la troisième personne'; but a distinction is to be drawn between indeterminacy and ambiguity, a point to which Apollonius seems sensitive (see synt. II 100, p. 203.14-19, where 3P pronouns and verbs are said to refer to 'very many' individuals, but formal coincidence is limited to the features of reflexivity and nonreflexivity). And proper names are, for Apollonius, homonymous or ambiguous in referring to several definite individuals, such as the two Ajaxes or the many royal Ptolemies, while Homeric pronouns are ambiguous between being reflexive and non-reflexive. I think more proof is needed that Apollonius would have seen indeterminacy and ambiguity as related in the way Lallot assumes.

32 Some further examples: certain adverbs coincide with the neut. nom. sing. or pl., or the dat. sing., of certain adjectives, as $\tau a \chi v ́, \pi v \kappa v a ́$, and $\kappa v^{\prime} \lambda \omega(a d v$. 120.1ff., 151.4ff., 165.30f., 200.16; and cf. synt. II 33, p. 150.8ff.); there is homophony of the conjunction and adverb iva (III 139, p. 388.9ff., and see further, p. 454); Attic prosody distinguishes the otherwise formally identical enclitic and conjunctional $-\delta \epsilon / \delta \epsilon^{\prime}$ and $-\gamma \epsilon / \gamma \epsilon^{\prime}(a d v .181 .29)$; $\alpha \dot{v} \tau o \hat{v}$ is ambiguous between the $3 \mathrm{P}$ gen. pronoun and the local adverb 'there' (176.8ff.). The ambiguity of $\dot{\epsilon} \rho \hat{\omega}$ at pron. 52.5 has already been noted (p. 448). Apollonius makes it a rule that properties of words not pertaining to their own peculiar êvvoıa, 'meaning', will not, despite even thorough-going formal identity between them, suffice to put them both in the same class: synt. I 76, p. 65.9-11; cf. Sluiter (1990) 64. 
'̇ $\lambda \epsilon \hat{\imath \nu}$ ', 'grant me the man to catch' (Il. V 118), is actually an instance of the figure hyperbaton (transposition), with the natural order of agent and patient of the verb reversed $(87$, p. 346.1 ; cf. 85 , p. 344.10 ; Itkonen [1991], 206 points out that deviant constructions involving prepositions and enclitic pronouns are also explained as cases of hyperbaton).

Lallot's first example of syntactic ambiguity is also of interest, for it is only doubtfully an example of ambiguity at all; and in this, as in other respects, it recalls

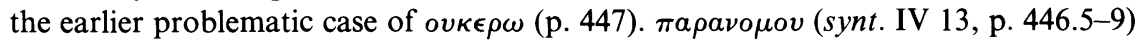
can be straightforwardly identified as an instance of the Stoic ambiguity species into which (it will be remembered) fall such lexeis as $a v \lambda \eta \tau \rho \iota s$ (see p. 448). Here, a sequence of letters or letter-sounds (or both) can be taken as one word ( $\pi \alpha \rho \alpha \nu o ́ \mu o v$, genitive of the adjective $\pi \alpha \rho a ́ v o \mu o s, ~ ' u n l a w f u l ')$ or as two ( $\pi \alpha \rho a \dot{~} \nu o ́ \mu o v$, 'against the law')..$^{33}$ It was observed earlier too that one of the reasons for the Stoics' having made the bearer of ambiguity a lexis-just such a sequence as this-was precisely to accommodate ambiguities of this sort, where neither an equivocal word(-form) nor an equivocal word-complex can be said to be in play. Apollonius introduces a distinction between being part of a word or lexis and being part of word-complex or logos (14, p. 446.10-13), a distinction corresponding to a dichotomy exploited here and elsewhere between 'compounding' of words, $\sigma v \dot{v} \theta \epsilon \sigma \iota \varsigma$, (as in $\pi a \rho \alpha \nu o ́ \mu o v, \pi \alpha \rho a ́ v o \mu o s)$

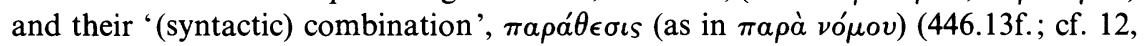
444.9f., $a d v$. 123.27; and cf. Itkonen [1991], 212). But, again, he nowhere hints at any doubt that such examples might not be genuine examples of ambiguity. ${ }^{34}$

Most interesting of all, perhaps, is Lallot's selection from amongst those 'nombreux exemples empiriques où différentes causes se conjugent pour rendres possibles

${ }^{33}$ It remains unclear whether the two readings would have been automatically distinguished in speech (by prosodic or junctural features), and hence unclear whether Apollonius has in mind homographs alone (in scriptura continua), or ambiguities in both media, spoken and written alike. Elsewhere he talks of features of pronunciation eliminating ambiguity, coincidence, and homophony (between nom. and voc. of pronouns and nouns: synt. III 40, p. 305.11ff,, pron. 52.16-21), and of prosody having the same effect (on indic. $\dot{\epsilon} \sigma \tau \dot{\epsilon}$ ' you are' versus imper. $\ddot{\epsilon} \sigma \tau \epsilon$ 'be!': synt. III 121, p. 373.11ff.; on the adverbs and conjunctions $-\delta \epsilon / \delta \epsilon$ and $-\gamma \epsilon / \gamma \epsilon$ : $a d v$. 181.29). Likewise, $1 \mathrm{P}$ sing. and $3 \mathrm{P}$ pl. imperfects are distinguished by prosody in Doric (synt. III 33 , p. $300.6 \mathrm{f}$.), and, thanks to the foresight of the inventors of the language, some postposed

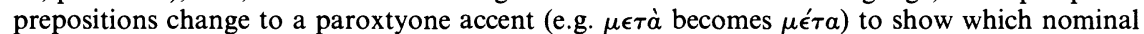
they are associated with (IV $10, \mathrm{p}$. 442.8ff.). The possessive pronoun oi and the dative of the personal pronoun oi are also distinguished by prosody (III 48, p. 314.7-11); in this instance, reference is made explicitly to ways of ' reading' a text $(314.7,10)$, suggesting that prosodic signs were not available to guide the reciter or silent reader; cf. $a d v$. 199.1f., 16f., with a distinction between pitch (a feature of pronunciation) and the addition of written iota mutum, with no effect on pronunciation. At synt. III 31, p. 297.18ff., Apollonius explicitly distinguishes between written and spoken forms: the written form $\nu \iota \kappa \hat{\omega}$ (itself shared by the $1 \mathrm{P}$ sing. indic. act. and the $2 \mathrm{P}$ sing. imper. med./pass.) differs from the written form $\nu \iota \kappa \hat{\omega}\langle\iota\rangle$ (3P sing. opt, 'he may win') by iota mutum, but the corresponding spoken forms are identical. All this tends to suggest that Apollonius was inclined to conceive of written and spoken versions (representations, if that modern jargon is not too misleading) of the same word as in part distinct, at least as regards formal coincidence, but not as regards syntax-which is what we would expect, despite the fluidity of Apollonius' metalinguistic terminology. Apollonius' careful approach to matters of punctuation is reported by D.T. Sch. 26.17-26.

${ }^{34}$ It may seem a curious thing to modern eyes that Apollonius feels it important to lay down diagnostic techniques for distinguishing such radically different forms of word association as compounding and combination; no doubt Homeric usage, perhaps coupled with the effects of contemporary scribal practice, is responsible. Stoic influence may also be at work: the pointer to this is the parallelism between syntactic and non-syntactic association assumed by two of the Stoic ambiguity kinds (see further, Atherton (1993), 360-62, 370f.). 
plusieurs constructions' $(1988,39)$. Yet Apollonius treats the ambiguity of Iliad VII $152 \mathrm{f}$,

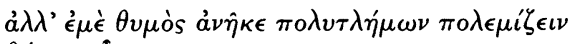

$$
\begin{aligned}
& \theta \alpha \dot{\alpha} \rho \sigma \epsilon \iota \stackrel{\dot{\omega}}{\omega}
\end{aligned}
$$

(synt. II 112, p. 212.5f.; the speaker is Nestor) as turning only on the ambiguity of $\dot{\omega}$. We can paraphrase these lines (much as Apollonius does, p. 212.7-14; cf. pron. 48.11ff.) as: (i) 'My heart persuaded me to fight with [i.e. to fight making using of] its courage'; or as: (ii) 'With [i.e. by the power of] its own courage, my heart persuaded me to fight the challenger'; or as: (iii) 'My heart persuaded me to fight with [i.e. against] his [sc the challenger's] courage' (where 'his courage' stands figuratively for the challenger himself).

For Apollonius, this line is a case of the systematic ambiguity of Homeric pronouns, at a time when reflexive and non-reflexive forms had not yet been formally distinguished (cf. II 90, p. 193.17ff.). Here, $\dot{\omega}$ could be 'compound' or 'simple'-that is, the reflexive or the non-reflexive pronoun (cf. synt. II 108, pp. 209.10-210.3). Yet Apollonius' solution appears arbitrary: 'And again one must understand that the verb [sc ' $a \hat{\nu} \hat{\eta} \kappa \epsilon$ ' 'roused up'], which does not occur in the 〈same〉 person as $\langle$ is referred to by $\rangle$ the pronoun [sc $\dot{\omega}$, 'his/its (own)'], produced the paraphrase [ $\left.\mu \epsilon \tau \alpha^{\prime} \lambda \eta \psi \iota v\right] a \dot{v} \tau o \hat{v}$ ' his' $\langle$ of $\dot{\omega}\rangle$ '; for the heart did the rousing up all by itself [i.e. not using something in its power, as in paraphrase (ii)], and the courage is not its possession [as in paraphrase (i)], but that of the challenger [as in paraphrase (iii)] (212.14-17).

Nothing, then, is said of different sorts of datives (to which Lallot's lucid explanation appeals, [1988], 39f.), and remarkably few other metalinguistic technical terms are applied. Any complexity in the cause of the ambiguity is wholly implicit in Apollonius' discussion, the focus of which is the pronoun; the details of the various syntactic groupings to which its different meanings give rise have to be gathered from the accompanying paraphrases. Reading (ii) is eliminated unceremoniously, although

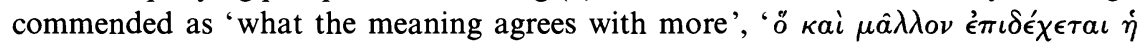
$\delta \iota c^{\prime}{ }^{\prime} \iota \alpha^{\prime}$ (212.10), while the favoured reading is never defended. Lallot is surely correct in seeing a syntactic ambiguity in these lines, but the single syntactic point made by Apollonius himself is brief and obscure: note how much needs to be supplied

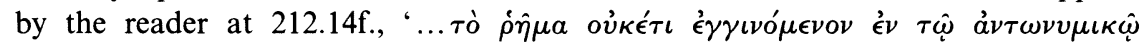
$\pi \rho \circ \sigma \omega \pi \omega$ '-literally, 'the verb not occurring in the pronominal person'-to make Apollonius' account intelligible. And the different meanings of the key pronoun are themselves explained, not by explicit description, but by way of paraphrases (such as ' $\tau \hat{\varphi} \alpha \dot{v} \tau o \hat{v} \theta \alpha{ }^{\prime} \rho \sigma \epsilon$ ' ' with its courage', i.e. the courage of the speaker's heart (212.8); ' $\tau \hat{\varphi} \dot{\epsilon} a v \tau o \hat{v} \theta a ́ \rho \sigma \epsilon \iota$ ' ' by its own courage', again, the heart's own courage (218.9); ' $\tau \hat{\varphi}$

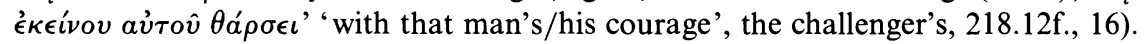

Apollonius' silence here on points of syntax is, in a way, understandable: his chosen topic is the Homeric pronoun, and it is this which motivates the quotation and discussion of these lines. But we can say at least that an opportunity is passed by to describe explicitly and in detail the effects which the ambiguity of the pronoun has on the construction taken as a whole. In particular, Apollonius does not explain how that ambiguity, in this context, is complicated by another: as the 'paraphrase' referred to in p. 218.16 confirms (' $\tau \hat{\varphi}$ a $\dot{v} \tau o \hat{v} \theta \dot{\alpha} \rho \sigma \epsilon \iota$ '), the reference of the key pronoun has to be cleared up even after the possibility of its being reflexive has been discounted.

Apollonius has no apparent interest either in examining possible ways of classifying this complex ambiguity. And his implicit 'classification' of ambiguities by 
terminology alone is always far too fluid to substitute for an explicit typology. (We shall see later that hand-in-hand with this indifference to classification and definition of ambiguity goes a lack of interest in classifying techniques of disambiguation-and that despite the importance of disambiguation for his own theories of language and of grammar.) Yet we have observed too that Apollonius was not alone in accepting as cases of ambiguity items we would probably want to treat instead as cases of confusion (here we suspected familiarity, direct or indirect, with Stoic material). If mistakes were made on that count, bad marks will have to be awarded to the Stoics and to many other ancient writers on ambiguity as well. Again, some at least of the sorts of ambiguity he discusses or mentions make regular appearances in the classification of ambiguity as that was practised in the grammatical and rhetorical traditions. Only once, however-in the case of (ostensible) double-accusative-andinfinitive ambiguities-, does he seem to have wanted to correct the current orthodoxy. So the reason for Apollonius' silence on the matter of ambiguity typology and its principles is unlikely to be that he found fault with all the material available to him and on that account declined to make use of it.

\section{V}

Let us start again. Apollonius uses the threat of ambiguity to explain certain departures from regularity in forms of words, and the reality of it to explain away apparent cases of grammatical incongruity. A key passage from synt. III 22, p. $288.5 \mathrm{ff}$., introduces and amply illustrates the principle that formal coincidence can free a construction from the charge of incongruity: one or more words apparently not fitting their place in a $\lambda o ́$ yos may turn out merely to share some formal feature (such as case or person) with a word which would, if present, genuinely produce incongruity (e.g. synt. III 27, p. 292.17ff.; cf. III 39, p. 305.7ff.; and see Sluiter [1990], 53; Itkonen [1991], 203-5). So ambiguity can conceal syntactic congruity; but it can also, on occasion, as Blank observes $(1982,46 f$.), conceal the opposite, incongruity, as with the construction of a singular verb with a neuter plural nominative case: this is genuinely incongruous, but seems not so because of the formal coincidence between neuter plural nominatives and accusatives (III 53, p. 315.16ff., esp. p. 319.1f.).

Coincidence is not always tolerated, however, and can be eliminated in a variety of ways, including actual change in form, to which Apollonius seems to have had, however, comparatively little recourse. Blank $(1982,37)$ cites one example of it, already described, of the masculine singular definite article. To this we can add the

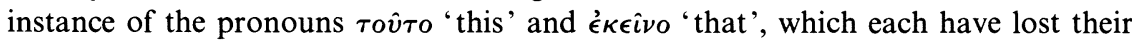
final $\nu$ in the nominative and accusative cases, in order to avoid confusion with the

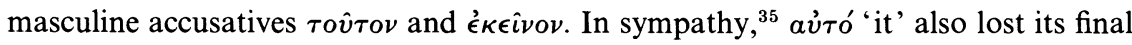
$\nu$, although it alone could take the article to signal the difference in gender and case; in Attic, an alternative form confirms this formal change ( $\tau \alpha \dot{v} \tau o$ ' $v$ 'the same $\langle$ thing $\rangle$ ') (I 80, p. 67.9ff., cf. 136, p. 112.1ff.; adv. 56.22-57.9, 179.22ff.). Features of prosody, punctuation, and pronunciation have also done away with the potential for confusion. ${ }^{36}$

${ }^{35}$ Here $\sigma v \nu \epsilon \kappa \delta \rho o \mu \eta '$ is surely corrected identified by Uhlig ad synt. I 78, p. 67.6 as 'false

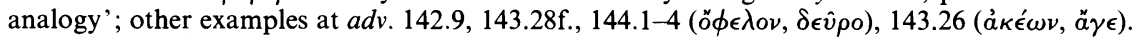

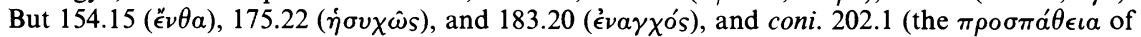
$\pi \circ \hat{v})$ are surely instances of genuine analogy.

${ }^{36}$ See $n$. 33. Such cases are listed by Lallot $(1988,41)$ amongst 'ambiguïtés apparentes', the appearance, $I$ take it, resulting from the incompleteness of the written (version of the spoken) form. 
Far more common than formal change or variation for elimination of ambiguities is appeal to what can be broadly characterised as contextual features, which may be syntactic or semantic-again, Apollonius himself makes no distinctions. We are told that 'such words as coincide formally lose their syntactic ambiguity thanks to sentential constructions' in which they appear (pron. 52.4-6; this generalisation is

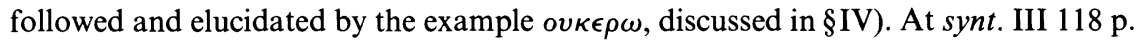
371.8 , we learn that, if one word in a complex is ambiguous, the part of speech 'used

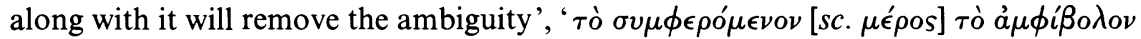

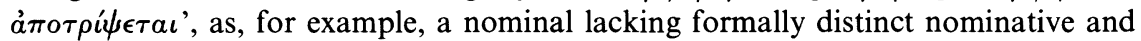
vocative cases can be disambiguated by a clearly indicative or a clearly imperative

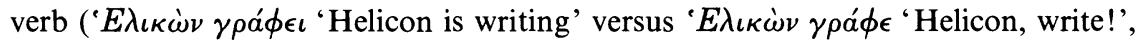
371.9-11). Matters become more complicated when the other component is also

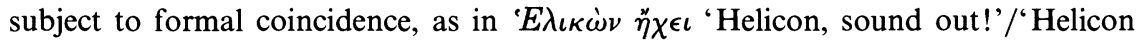
sounded out' (372.5); ' ... in which construction there is once more need of additional parts 〈of speech〉', such as a nominative article $(\dot{o})$ or an interjection $(\hat{\omega})$ to distinguish the nominative + indicative from the vocative + imperative construction. (6f.). Furthermore, a vocative case constitutes a complete utterance in itself, and no

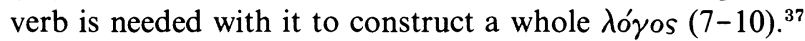

Such instances of disambiguation can be classed as broadly syntactic, as can those at synt. III 139, pp. 388.10-389.3 (the mood of a verb can help distinguish adverbial from conjunctional iva ('where' versus 'so that'); cf. coni. 214.11-17, 243.11ff., and see Sluiter [1990], 144, 150) and III 49, p. 314.12ff. (syntax distinguishes between formally coincident possessive and relative pronouns; cf. III 102, p. 204.18ff., pron. 48.11ff.). But semantic disambiguation is also found: thus, occurrences of the nominative and vocative pronouns sharing the form $\sigma v^{\prime}$ 'you' can sometimes be distinguished by the meanings of the verbs with which they are associated (for only the nominative occurs with verbs of being and naming, pron. 52.4-10; cf. $a d v$. 123.1-6, synt. II 47, pp. 159.13-160.1, III 37, pp. 303.18-304.5). The adverb ä $\gamma \epsilon$ 'Come!' is prohibited by its meaning ( $\sigma \eta \mu \alpha \iota \nu$ ' $\mu \epsilon \nu o \nu)$ from association with all moods but the imperative, and so makes possible a distinction between verb forms in the imperative and indicative moods if these coincide: ' ... so that ambiguous verbs too, because of the syntactic idiosyncracy 〈of this adverb〉, lose their ambiguity, thanks to its peculiar syntactic association' ( $a d v .123 .13-15$, and generally 10-16; cf. synt. III 117 , p. $371.5 \mathrm{ff}.){ }^{38}$ Sentences such as 'Yesterday I am writing' are ruled out on grounds of semantic unacceptability (cf. Itkonen [1991], 205), just as construction with certain temporal adverbs, in virtue of their meaning, can remove ambiguity of tense in participles and verbs ( $a d v .123 .16 \mathrm{ff}$.). Note too the distinction between $\delta \iota a^{\prime}$ 'by the agency of' and $\delta \iota a^{\prime}$ 'via' (both with the genitive) on semantic grounds at $a d v$. 199.5-11.

Sometimes both syntax and semantics may be involved, as in the case of the doubleaccusative + infinitive constructions, where the natural priority of agent over patient of an action determines syntactic (ordering) priority in oratio obliqua as it does in oratio recta (synt. III 84-6, pp. 344.1-346.2). The pronoun $\sigma v$ can only be constructed

${ }^{37}$ Cf. III 103, p. $358.14-359.3$, 116f., p. $369.8 \mathrm{ff}$, and also 111 , p. $364.8 \mathrm{ff}$., on homophony between the imperative and the hortatory mood.

38 This forms part of a discussion ( $a d v$. 123.1ff.) of the way in which the meanings of some adverbs can limit their syntactic associations (cf. Sluiter [1990], 80, 92, 96). Incongruity is not mentioned explicitly, but it is clear that constructions of á $\gamma \epsilon$ with indicatives is impossible (esp. 123.10f., 12)-a result of what we would call a 'selectional restriction'. This point serves to bring out Apollonius' primarily semantic conception of syntax, on which see further, $\S 7$. 
with verbs of being and naming in the nominative, as we saw a little earlier; but Apollonius also appeals to syntactic phenomena to show that $\sigma v$ is often-standardly, in fact-used with indicatives (synt. II 35-41, pp. 302.3-307.8). ${ }^{39}$ The word $\epsilon \mu o \hat{v}$ is inflected from $\dot{\epsilon} \gamma \dot{\omega}$ when construed with a verb (II 119, p. 218.5-13, 120, pp. 218.14-219.1), from '́ $\mu$ ós when construed with a nominal denoting the object possessed (123, p. 221.7-12). At synt. I 65, p. 56.3ff., the homonymy of proper names is said to be removed by attaching to them epithets ('Telamonian Ajax') or definite descriptions ('Apollodorus the Athenian', 'Trypho the grammarian').

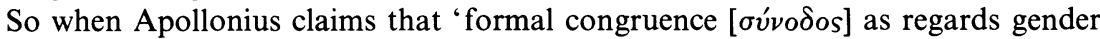
[i.e. in definite articles, such as the genitive plural $\tau \hat{\omega} \nu$ ] is removed by the agency of the accompanying parts of the sentence, just as the other parts 〈of speech〉 with several meanings $\langle$ signified $\rangle$ by one word $[\phi \omega \nu \hat{\eta} s]$ have their ambiguity of expression resolved by the construction which precedes them' ${ }^{40}$ (synt. I 39, p. 35.12-15), we should be put in mind of a very generously construed 'contextual' process. Thus, after one formal/syntactic illustration, Apollonius envisages (I 40, p. 36.11-13) the genitive plural of the definite article, $\tau \hat{\omega} \nu$, being disambiguated by an accompanying

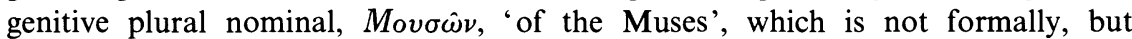
semantically, feminine. This conception of disambiguation is at least consonant with Apollonius' conception of syntax, which will occupy us later.

\section{VI}

What is striking, over and above Apollonius' now obvious indifference to the classification of ambiguities or of disambiguation procedures, is that it does not seem to have been felt as a difficulty for the theory of formal regularity or analogy at the level of inflection that, were it not for certain safety nets, the principle of regularity would inevitably, in some cases, lead to obscurity, to impairment of language's function as the carrier or medium of thought. (It has also led to some unnecessary formal alterations, as we saw in the case of $a \dot{v} \tau o$; these are allegedly accounted for by the similarity in function of avंós to other pronouns, the formal alteration of which was genuinely motivated by considerations of clarity.) I assume that Apollonius accepts this situation because he takes such deviations to be themselves rule-governed and rationally explicable. In part this means that they can be formally matched to recognised rules for linguistic variation, notably the famous quadripertita ratio 'add/subtract/transmute/transpose'. ${ }^{41}$ But it must also mean that any departure from regularity has itself to be well-motivated. It cannot be enough for the deviation to be formally derivable from some regular original by a regular pattern. An account must also be offered of why deviation occurs at all: otherwise it would be possible, for any alleged 'deviant' form, to 'explain' it by applying the preferred regular pattern to some supposed 'original'.

39 With verbs of being: 303.16-304.5; in co-ordinate constructions: $304.5 \mathrm{ff}$; with conjunctions: $304.11 \mathrm{ff}$; with other indicative verbs: $305.11 \mathrm{ff}$; with participles: $303.14-16$. (As Schneider [1902], 78 points out, Apollonius' position on the cases of $\sigma v$ is different in the Syntax and the On pronouns, but the point in question here is unaffected.)

40 Although Apollonius appears to speak of 'the construction which precedes them', ' $\tau \hat{\eta}$ $\pi \rho \circ \epsilon \iota \eta \mu \epsilon^{\prime} \eta \sigma \sigma v \nu a^{\prime} \xi \epsilon \iota$ ' (p. 35.14), his examples of contextual disambiguation do not conform to this odd and unnecessarily restrictive pattern-indeed, the very next case he describes ( $p$. 35.16) has an ambiguity of gender resolved by a succeeding participle. Perhaps he means rather '... by the sort of construction we have already discussed', but that is surely too narrow a description for so general and generous a ruling, and the point remains puzzling.

41 On linguistic 'pathology' in Apollonius and elsewhere: Blank [1982], $41 \mathrm{ff}$. 
In a negative way, Apollonius is well aware that ambiguity cannot be invoked to explain deviations ad lib. He claims arbitrariness in, for example, the case of the grammarian Trypho's derivation of the exclamation $\dot{\omega} \tau \hat{\alpha} \nu$ 'Sir'. Trypho had argued that this was derived from the exclamation $\dot{\omega}$ ' $O$ h!', lengthened by addition of the syllable $\tau \alpha$ (on the lines of $\delta \hat{\eta} \tau \alpha$ 'indeed/to be sure'), the final $\nu$ having been added to distinguish it from the word $\dot{\omega} \tau \alpha$ 'ears' (adv. 159.15ff.). Apollonius' complaint is that Trypho has failed to explain the word's curious phonological properties (the length of the $a$, the double accentuation), which, not its history, constitute the real puzzle (19-22). What is more, consonants or vowels cannot be added or subtracted at will on the grounds of avoiding ambiguity, 'when almost every word is subject to ambiguity' (22-6).

Trypho is again the target at synt. I 74ff., p. 63.11ff., where he and Apollonius disagree about the classification of the word $\dot{\omega}$. Trypho is charged with talking 'drivel' (' $\lambda \eta \rho \hat{\omega} \delta \epsilon \varsigma^{\prime}, \mathrm{I} 84$, p. 72.9 ) in arguing that the failure of $\dot{\omega}$ to distinguish for gender is no objection to its being an article, since the genitive plural $\tau \hat{\omega} \nu$ ' of the' fails the same test (72.6-8): the formal coincidence of $\tau \hat{\omega} \nu$, as of all articles, Apollonius observes, 'mimics the formal coincidence of nominals as regards gender' (72.11f.). Many other passages can be found where an appeal to ambiguity to explain such-and-such a form, or such-and-such a phenomenon, is refused as ill-founded, or illicit, or as mere raising of hares; such appeals too can be so much 'drivel', since 'formal coincidences are without limit' (pron. 92.10f.). ${ }^{42}$

Again, the suggestion that definite articles were introduced in order to distinguish cases of nominals which do not reveal gender-and so remove a possible source of ambiguity-is rejected by Apollonius (synt. I 38-41, pp. 35.5-38.4). His first objection to it is that it offends against the principle that each part of speech has its own independent force or meaning, and cannot be explained as simply serving to remove the ambiguity of another part of speech (35.10f.). The whole context, if anything, will disambiguate (35.12-15). What is more, there are instances where ambiguity persists despite the presence of the article (as with genitive plurals); and there are instances too where articles are used even where gender is already indicated in some other way (35.19-38.4).

42 The accentuation of $\tau \omega^{\prime} \delta \epsilon$ is the topic at pron. 92.6ff. Unfounded appeals: $71.2 \mathrm{f}$. ( $a \lambda \lambda \lambda^{\prime} \lambda$ ovs not ambiguous between the nom. and oblique cases); synt. III, p. 365.4f., 106, p. 360.6ff., IV 6, p. 437.4ff. (no homophony of $2 \mathrm{P}$ hortatory and imperative mood forms, of $1 \mathrm{P}$ imperatives and indicatives, or of prepositive and postpositive articles (i.e. of definite articles and relative pronouns) in (what we call) indefinite constructions). Hares: synt. I 95, p. 80.6ff. (although they do not themselves distinguish for gender, some pronouns do not associate with articles; but there is a reason for this, I 96ff., p. 80.13ff.). Illicit appeals: synt. II 88, p. 192.9ff. (aúzós not used to distinguish the gender of pronouns); IV 67, p. 488.10ff. (that definite articles distinguish ambiguous nominals (sc. proper names: cf. II 23, p. 142.4-7) is not a genuine parallel for their alleged use in distinguishing between syntactic and non-syntactic association of adverbs and prepositions). Apollonius also finds formal coincidence where others deny it, as with infinitives (synt. I 51, p. 45.3-7) and *'é $\mu \alpha v \tau o ́ s$ (II 143, p. 238.7ff.). Sluiter (1990), 126f. is right to observe that for Apollonius coincidence is 'one of the realities of language', and that he refuses some appeals to it in grammatical explanation. But she misses all but one of the cases where forms serve to distinguish ambiguities (the exception is Attic $-\gamma \epsilon / \gamma \epsilon^{\prime}:$ see $n$. 32), and fails to see that, if 'the context will in principle solve any ambiguities caused by' coincidence (not anyway true in practice (see pp. 460f.), and never defended by Apollonius), such formal means of distinction will be redundant, and Apollonius' doctrine, as a result, far from 'coherent'. Sluiter also notes (1990), 126, n. 332, that the confusion and unintelligibility resultant on formal coincidence may be the real objects of avoidance, yet does not ask why this should have to be so if context always disambiguates: see further, pp. 457-460, 460f., and §VIII. 
So Apollonius apparently does believe that explanations of linguistic deviations as prophylactics against ambiguity must, at the very least, not conflict with other, say, metatheoretical, rules (e.g. one part of speech cannot be accounted for merely as a means of disambiguation for another) or with the phenomena (e.g. definite articles do not, as a matter of fact, consistently distinguish gender of nominals). But has he anything more to offer than these negative constraints? Ambiguity for Apollonius, as for almost everyone else in antiquity, was primarily a defect, something to be eliminated one way or another; the assumption, almost always, is that ambiguity interferes with the clear expression and communication of thought. Thus Aristotle makes avoidance of ambiguity one of the conditions for writing good Greek ( $r h$. III 5 1407a32ff., cf. 2 1404b37-1405a2); in his little pamphlet On linguistic sophisms Galen argues that obscurity is the sole linguistic defect and has ambiguity as its sole cause (Ch. 2, 4.11-7.10 G 7-12 E) $;^{43}$ the Stoics clearly regarded ambiguity as a cause of one of the stylistic vices, obscurity (cf. Galen soph. Ch. 4, 13.13 G 22 E, 13.16f. G $22 \mathrm{E}, 14.2 \mathrm{G} 23 \mathrm{E}$; Theon prog. 82.3f., 7f., 26) $;{ }^{44}$ grammarians and rhetoricians tend to treat it, in a more orthodox way, as one cause of the stylistic defect, obscurity; ${ }^{45}$ and so on. Apollonius is presumably subscribing at least to an association of ambiguity with obscurity when he explains that oratio obliqua constructions with two accusative cases 'do not make clear which is the agent and which the patient' (synt.

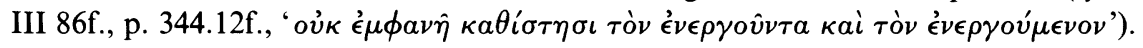
The (by now familiar) ambiguity of $\dot{\epsilon} \mu o \hat{v}$ means that it 'is not made clear by its sound-

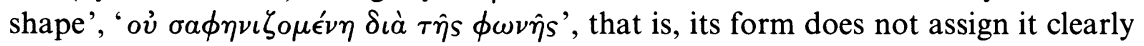
to the personal or to the possessive pronoun (synt. II 117, p. 217.2f.). Again, the change of the masculine singular definite article from * cós to $o$ is said to avoid the appearance of incongruity (synt. I 80, p. 68.1-3), and this makes most sense if incongruity is seen as making sentences unclear or even (the limiting case of inclarity) unintelligible (cf. synt. I 41, p. 37.7; note I 65, p. 56.5, where the use of common and

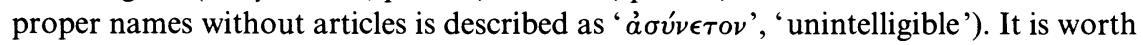
observing, in this connection, that instances of 'poetic licence', such as omission of prepositions, are said to be 'returned to clarity, and ordinary parlance', under the

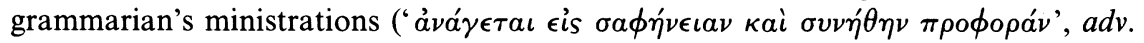
200.8f.).

This linking of ambiguity with lack of clarity is not in itself outrageous. Far from it. What is strange is that Apollonius nowhere attempts to draw together, let alone justify explicitly, the sorts of explanation he believes appropriate where ambiguity occurs or is eliminated. I would suggest that this methodological silence is the result of a more basic failure. Apollonius appears never to have offered a convincing, wellargued general account of language which would make such explanations theoretically and methodologically inevitable-or which would even, minimally, make them look anything more than intuitively plausible. ${ }^{46}$ In the case of syntax, the semantic content of any sentence seems to have been assumed by Apollonius to be single and in some way correct, so that the grammarian's job is to explain cases where this well-ordered semantic unity has not or appears not to have been matched at the linguistic level (cf. Blank (1982), 23f.). Apollonius' confident assumption is that,

${ }^{43}$ Mode of reference: $n .22$.

44 See further Atherton (1993), 87ff., esp. 88 n. 52.

45 See n. 5.

46 We might compare Varro's claim that words are mostly regular in inflection and derivation because that makes them easier to learn and remember: de lingua latina VIII iii. Varro does not present this as an application of the principle that human languages must have properties which make them learnable by human beings. 
although it may on occasion force language to abandon strict inflectional regularity, or raise the spectre of incongruity, ambiguity merely conceals the original perfect congruity of words, meanings, and structures, whose pristine correctness is recoverable by the appropriate methods; and that if a form or construction occurs which might be open to more than one interpretation, a single and precise meaning can (with a very few exceptions) be distilled from the context as a whole.

But why should this be so? Even if we take on board the notion that regularity can be semantically counter-productive, it remains far from obvious that language is always or so often successful. It has to be assumed that the appropriate counterweights, so to say, always or almost always balance out an ambiguity, so that, where necessary, semantic-cum-pragmatic considerations take precedence, and meaning is conveyed by transgressing formal regularity, or by contextual factors. If, in contrast, some ambiguities turn out to be recalcitrant, whatever is done to them, it would be strange if others happened to be eliminable; equally strange if they did not threaten Apollonius' broad assumption that language is good at what it does. Or, reversing the point, if some formal coincidences actually present in language cause no difficulties, it is not clear at all why others should have been eliminated to avoid confusion. In a word, why assume that the semantic interventions themselves conform to some regular pattern within a justifiable and coherent conception of language?

These objections will be clearer, I think, with the help of a few examples. The examples will show what may have been long suspected: that Apollonius' programme is fraught with inconsistencies.

First, as we have seen, formal concinnities may be found without ambiguity of the whole, because context serves to clarify what is meant. An illustration, drawn from Apollonius' criticisms of those who thought articles were invented to make gender clear, is the sentence 'Although she was modest, Helen was kidnapped by Alexander',

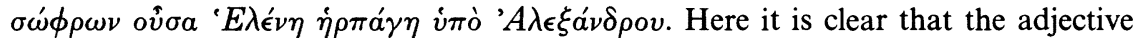
'modest', $\sigma \omega \dot{\phi} \phi \omega \nu$, is feminine, although no article is present in the Greek; both the participle 'being' ov $\sigma \alpha$ and the proper name 'E $E \lambda^{\prime} \nu \eta \eta$ 'Helen' are, however, clearly feminine in form. Conversely, the nouns $\theta \epsilon o$ s 'god/goddess/divinity' and i $\pi \pi \circ s$ 'horse/stallion/mare' can be distinguished for gender by adding the article (albeit not in all grammatical cases) (synt. I 39, p. 35.15-17, I 41 p. 37.1f.). The obvious question is: why have these instances been left to stand? If they can be coped with contextually one way or another, why should other instances of formal coincidence not have been as well? Avoidance of formal co-incidence is also invoked to explain the absence of a vocative form of 'és,s, a form which would be identical with the accusative case 'été (synt. III 47, p. 312.15f.). Why should it have been eliminated, and not $\sigma \omega \dot{\phi} \phi \omega \nu$, $i \pi \pi o s$, and their like?

Then there is the change in form, already remarked on, of the neuter pronouns

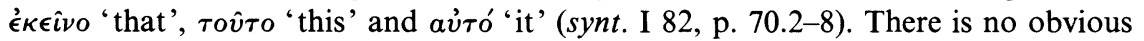
reason why comparable formal changes should not have occurred in, say, adverbs coincident with neuter singular or plural adjectives; but here the process of disambiguation takes the form of ringing the changes of the cases of the nominal apparently associated with the ambiguous form in question (e.g. $a d v$. 120.1-15). No rule is given as to when form provides the solution, and when context does so. And it is remarkable that coincident inflection of articles, which mimics that of the nominals they accompany (synt. I 84, p. 72.6ff.), effectively prevents articles from functioning as indicators of gender (cf. synt. I 40, p. 36.6ff.). Ease of construal, and so intelligibility, in one dimension, acts as a restriction on intelligibility in another. On 
the other hand, pronouns, although relatively few in number compared with nouns, tend not to follow simple, straightforward inflectional patterns analogous to one or other nominal inflection pattern, precisely because of their function-their rôle, in any grammatical case, of substituting for any noun (II 24, p. 143.9ff., esp. p. 144.4-8). It is odd that such resources were available in the one instance, and not the other: odd, too, that irregularity improves semantic or communicative efficiency in one case, impedes it in another.

At one juncture formal coincidence is called on to explain, not an apparent, but a genuine instance of incongruity: the use of singular verbs with neuter plural subjects (III 53, pp. 318.5-319.2; cf. Blank [1982], 46f.). The identity of form of nominative and accusative neuter plurals is precisely what makes the irregularity of the construction 'hard to grasp', ' $\delta v^{\sigma} \sigma \lambda \eta \pi \tau o \nu$ ' $(319.1)$, for there are perfectly regular constructions which look exactly the same, ones in which the neuter plural is (what traditional grammar calls) object, not subject, of the verb. Here, as far as users are concerned, Apollonius must admit that inflectional phenomena have taken precedence over syntactic regularity. Why, then, should users' acceptance of irregularity stop here? If it does not interfere overmuch with communication, there seems no reason to make it so important a factor in linguistic explanation. And it is not enough, either, to secure the ideal of general intelligibility for it to be shown, case by case, that intelligibility predominates: not enough, that is, where intelligibility rests on the principle of rationality and regularity, as it must for Apollonius. What is needed is a taxonomy or hierarchy of rules, ordered according to some general theory of the functions and properties of language(s): none is offered or attempted.

Another sort of objection arises from Apollonius' criticisms of Trypho. Trypho, it will be remembered, wanted to explain the final $\nu$ of the exclamation $\hat{\omega} \tau \hat{\alpha} \nu$ as a way of avoiding confusion with the noun 'ears' $\dot{\omega} \tau a$. Part of Apollonius' complaint was that it would be 'absurd', ' $\gamma \epsilon$ '́oı

to offer additions or subtractions of consonants as explanations, on the grounds of formal coincidence, when practically every word $\left[\lambda \epsilon^{\prime} \xi \iota s\right]$ is open to ambiguity [í $\left.\pi^{\prime} \dot{\alpha} \mu \phi i \beta o \lambda o \nu \pi i^{\prime} \pi \tau \epsilon\right]$, and one absolutely must not add or remove vowels or consonants on account of the ambiguities which accompany 〈the formation of words〉.

(adv. 159.22-5)

First, the admission that ambiguity by formal co-incidence is almost universal is fatal to the consistency of Apollonius' use of ambiguity as an explanatory device. If practically any word-form has at least one non-synonymous duplicate, how can it be reasonably claimed that only this or that form-such as the vocative '́ $\epsilon \dot{\epsilon}-$-has failed to appear in the language in order to avoid ambiguity? The admission is not casual; elsewhere Apollonius allows that 'cases of formal coincidence are without number',

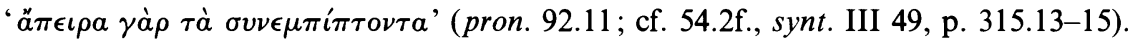
Second, Apollonius can be found guilty of another, more particular inconsistency. He argues here that adding or subtracting letters at will is unacceptable. Yet it will also be recalled that he himself claimed a history for the masculine singular definite article: first * $\tau o s$, then $\dot{\delta}$, to $\dot{o}$, the last change being made to avoid confusion with the relative pronoun (I 80, p. 67.10-12). Why is elleipsis allowable here, but pleonasm disallowed in the case of $\dot{\omega} \tau \hat{\alpha} \nu$ ? If because there is more likelihood of confusion between $\dot{o}$ and os (both articles, for Apollonius) than between an exclamation and a noun, what is needed is a good firm rule about when phonological changes follow meanings or grammatical categories: and we do not get one. And that is so even though Apollonius is able to offer some evidence for the nature of the original forms of $\dot{o}$ (I 80, p. 68.3-12, 81, p. 68.12ff., adv. 179.22ff., pron. 56.22-57.9). Indeed, Apollonius' appeal to ambiguity here is suspiciously under-determined. Elsewhere 
(synt. III 49, p. $314.12 \mathrm{ff}$.) he is clear that the constructions peculiar to the possessive and relative pronouns are distinct (nouns with the former, verbs with the latter), and that coincident forms can be distinguished in this way. Why should the different constructions into which definite articles and relative pronouns enter not have served the same purpose for them? The same may perhaps be true of the variation in mood, subjunctive as against indicative, which helps distinguish conjunctional from adverbial iva (III 139, p. 388.9ff.). Is any limit specifiable in principle on how much guidance is needed in cases of ambiguity, any more than on what sort of guidance is appropriate? Apollonius seems to have no answer.

One last example. Recall once more that Apollonius describes the word or wordform '́ $\mu o \hat{v}$ as the genitive case of two words or lexemes, the personal pronoun '́ $\gamma \hat{\omega}$ and the possessive pronoun '́ $\mu$ ós. He adds that in some dialects a formal distinction is made between the two, and that he supposes that Homer himself 'recognising the ambiguity of the form, expressed the personal pronoun in almost every dialect' (that

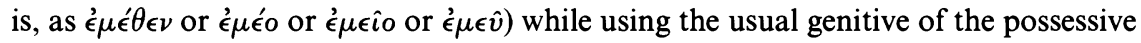

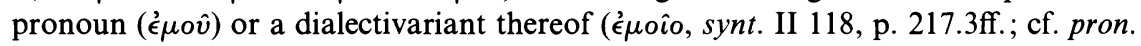
64.25-7). Two questions arise. If Homer has these resources available to him, why do others not continue to exploit them? Presumably, because different dialects have different resources (I am assuming, for the moment, with Apollonius, that there is such a thing as a Homeric dialect or usage), and because there are rules even against such eminently useful borrowings (as, say, Doric alone distinguishes certain persons in the imperfect by prosody, synt. III 33, p. 300.6f.). Apollonius himself remarks that poetic, more than ordinary, usage has tended to preserve a formal distinction amongst the three types ('where/whither/whence') of local adverbs ( $a d v .202 .14-16$ ), but is confusingly parsimonious with prepositions (199.20f.). What remains puzzling is that one usage (the Homeric), and no other, should have had these different forms available for the two sorts of $\dot{\epsilon} \mu o \hat{v}$-especially when, as Apollonius argues, their different constructions will disambiguate anyway (synt. III 119, p. 218.5-13; cf. 120, pp. 218.14-219.1). Either the ambiguity is not, then, really troublesome-in which case, why did Homer go to all the trouble of avoiding it, and why should other comparable ambiguities cause problems?-or it is-in which case, why have comparable linguistic resources not become available in other dialects of Greek?

And Apollonius does, apparently, concede that ambiguity sometimes persists, and in such a way as to affect meaning - unlike those cases, labelled 'techniques' by Lallot $(1988,40)$, where all that is at stake is grammatical description. In such instances, no reconstrual of the ambiguous form transforms a sentence from incongruous to congruous; and context is equally unhelpful. Meaning is hardly affected at all in two Homeric lines apparently open to ambiguity (Iliad XIV 100, XXIII 387) ${ }^{47}$ But the

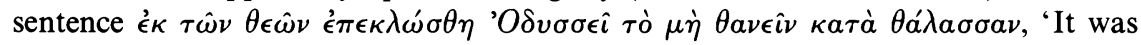
assigned as his lot to Odysseus by the gods that he would not die at sea' (synt. I 39, pp. 35.17-36.1), remains for Apollonius genuinely ambiguous-are 'the gods' masculine, or feminine, the Fates?-despite the presence of the definite article

47 The first ( $a d v .177 .29-178.1)$ is another example of the Stoic kind described in $\S$ IV (either $\ddot{a} \lambda a \delta \epsilon$ 'seaward' or $\tilde{a} \lambda \alpha \delta^{\prime} \epsilon^{\prime}$ 'but $\langle$ to $\rangle$ the sea') - with hardly any change in meaning. The second is treated in two different places by Apollonius: at synt. III 48, p. 314.7-9, he leaves interpretation of the line open; but at II 115, pp. 214.11-215.6 he apparently rejects one reading of the crucial pronoun, oi, dat. sing. of the personal pronoun (versus oi , 3P sing. possessive pronoun), as being favoured only by the frequent substitution of datives for genitives in Homer. Such change of accent in enclitics, he remarks, results in removal of formal coincidence (48, $\mathrm{p}$. 314.6f.; the problem presumably arises in writing, because of the absence of prosodic signs); and so Apollonius seems not to regard this as a genuine ambiguity. See already n. 33 . 


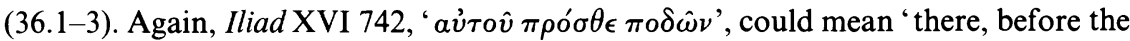
feet [of Hector's charioteer]' or 'before his feet' ( $a d v .176 .15-19)$. If the language has failed in these cases - failed, that is, to convey a single meaning - why should that be so? What, if anything, is special about these cases? Apollonius does not tell us.

\section{VII}

It might be objected that, whatever we make of the inconsistencies in his application of the principle of semantic efficiency, as it might be called, accusing Apollonius of failing to justify it on theoretical grounds is unfair. $\mathrm{He}$ is, after all, 'only a grammarian', not a philosopher of language, and it is surely the philosopher's job to provide such basic explanations of the nature and functions of language, the grammarian's to demonstrate the regularity of the phenomena which agree with that basic conception. But that would, I feel, be seriously to misunderstand Apollonius' own understanding of the grammatical enterprise. His conviction is that correctness - consistent, intelligent, correctness - is impossible without a reasoned account of any given, problematic, linguistic phenomenon (cf. Blank [1982], 7-10), and this is true even though he combines a rationalist methodology with a programme to demonstrate the acceptability of (most) good, received usage (see esp. pron. 113.17ff., adv. 199.16f., synt. I 60, p. 51.1ff., with Blank [1982], 14; Siebenborn [1976], 54f.).

Yet Apollonius cannot convince us that his programme is the right one without convincing us first that the conception of language on which his method rests is also the right one: the conception which makes language both rationally explicable, in the complex way adumbrated in previous sections of this paper, and successful, as an expression and communicator of thought, precisely in virtue of that matrix of rationally-explicable regularities. But no more than a gesture toward such a conception, not a rigorous defence of it, is made. Most notable in this respect is the long justification of the place of syntax in grammar at the start of the Syntax (I 2, pp. 2.3ff.). Here a complex analogy is constructed between the word and its constituents,

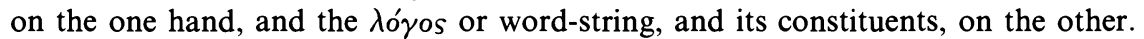
The elements (the letter-sounds forming syllables) and syllables (forming words),

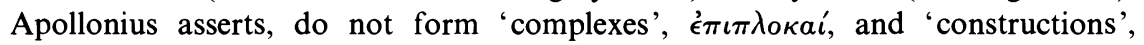
$\sigma v \nu \tau a ́ \xi \epsilon \iota s$, at random. He goes on:

And it is clear that it follows that the words $[\lambda \epsilon \xi \epsilon \iota s]$ too, being a part of the syntactically

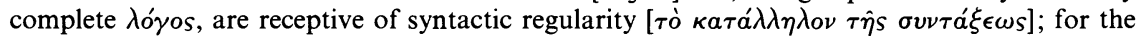

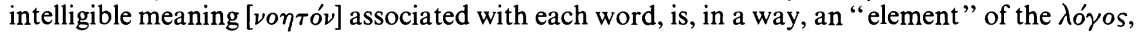

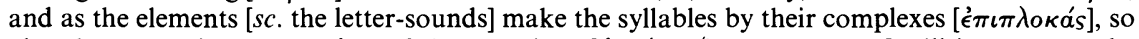
also the syntactic construction of the meanings [ $\left.\dot{\eta} \sigma v_{\nu} \tau \alpha \xi \iota s \tau \hat{\omega} \nu \nu o \eta \tau \hat{\omega} \nu\right]$ will in a way make 'syllables', ${ }^{48}$ by the weaving together [' $\left.\pi \iota \pi \lambda \circ \kappa \hat{\eta} s\right]$ of the words. And again, as the word is formed from the syllables, so the complete $\lambda$ ó $\gamma o s$ is formed from the congruent association of

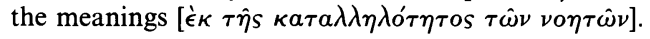

(synt. I 2, pp. 2.8-3.2)

Here Apollonius is distinguishing the syntactic association of meanings from the syntactic association of words with meanings, and this conception of syntax as also

48 These 'syllables', I take it, are phrases, or rather the semantic counterparts of phrases, units of meaning larger than words, but incomplete, as compared with the syntactically complete

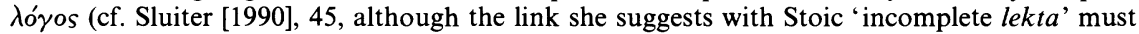
be indirect). Priscian's adaptation of this passage (which is very close to a translation of it) reads: 'sic etiam ordinatio intelligibilium imaginem quandam syllabae perficit adiunctione dictionum', 'for thus the ordering of the intelligibles produces a sort of likeness of the syllable by the association of the words' (inst. gr. XVII, p. 108.16ff.). 
or as primarily semantic is presumably Stoic in origin. ${ }^{49}$ But he is content to assert that the meaning of a word is 'in a way' an element of the complex: there is no argument that meanings do work like this, and no explanation either of the relation between the two levels. It is simply claimed, not demonstrated, that from the (supposed) fact that there exists regularity in the associations of letter-sounds and syllables 'it is clear that it follows that' (p. 2.8f.) there exists syntactic congruity of words.

Indeed, Apollonius' appeal to the already long-established science of orthography must leave us unmoved. (Apollonius himself regards it as not more than 'not implausible', 'ov่к ámíavov', synt. I 8, p. 7.6.) His appeal is in essence no more than the proposal that, just as wrong spellings left uncorrected by pronunciation can be put right by orthographic principles, so solecisms can be corrected by scientific knowledge of syntax (8-11, pp. 7.6-12.7). The comparison is the methodological counterpart of the comparison of different categories of words to vowels and consonants $(12, \mathrm{pp}$. 13.1-15.6), and of the lengthy (13-35, pp. 15.6-33.8) demonstration that the lettersounds, the parts of speech, and the various properties of the parts of speech, have

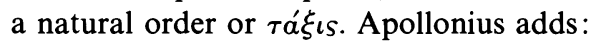

Perhaps some people, less experienced in the field, console themselves for their ignorance with the idea that there is no need to spend time on such investigations, and assume that such things have been imposed by chance. ${ }^{50}$ But they will have to assume too that nothing is in order or

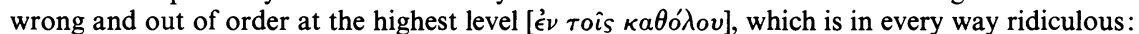
for, if you grant it in some cases, you must grant it in all. (I 13, p. 16.6-11) ${ }^{51}$

This criticism of course misses the crucial point that chance precisely eliminates the categories 'correct' and 'incorrect'. Apollonius has assumed too that pronunciation, spelling, syntax, and such matters as the order of the nominal cases are all open to correction and subject to correctness in exactly the same way. Now, even if we grant the existence of a single 'correct' orthography for each word, this must itself be a matter of convention (as to which inscriptions correspond to which sounds), and 'correct' syntactic relations and properties, although constituting an orderly and rulegoverned system, may be matters of convention no less. Yet that would undermine Apollonius' conception of grammar as a rationalist science dealing with naturally ordered phenomena, ${ }^{52}$ whose natural relations and hierarchies the grammarian discovers, and whose rule-governed behaviour he analyses. As Blank $(1982,17)$ has pointed out, Apollonius seeks to explain, to find the true causes of, syntactic

49 Cf. Blank (1982), 31-4, Frede (1978), 55-8. S.V.F. II 148, however, pace Blank (1982), 31, ascribes to Chrysippus no more than a point of terminology (that 'parts of speech' are $\sigma \tau o \iota \chi \in \hat{\imath} a$ ); the generative story (letters produce syllables, which produce words, etc.) appears to be the source's own.

${ }^{50}$ The term ' $\tau \epsilon \theta \epsilon \mu a \tau i \sigma \theta a \iota$ ', p. 16.8, deliberately recalls the etymological principle that some words are arbitrary impositions $\left(\theta \epsilon^{\prime} \mu \alpha \tau \alpha\right)$, all others being derived from these in (more or less) regular fashion.

51 On this passage, see also Blank (1982), 12f. (my translation differs from his at a number of points).

${ }^{52}$ Cf. synt. I 61, p. 52.4f., "when certain cases are in dispute, the products of reason, with a kind of natural consequentiality [ $\mu \epsilon \tau \alpha$ ' $\tau \iota \nu o s \phi v \sigma \iota \hat{\eta} s \pi \alpha \rho a \kappa o \lambda o v \theta \dot{\eta} \sigma \epsilon \omega s]$, will remove any syntactic impropriety'; also II 69, p. 177.1, 'what must be worked out is whether this property [sc. a certain sort of prosody] is a result of a sort of natural consequence [ $\kappa a \tau a$ ' $\tau \iota \nu a \phi v \sigma \iota \kappa \dot{\nu}$

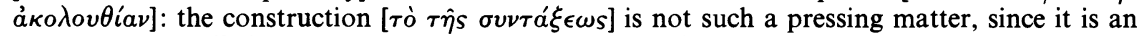
obvious fact [ $\pi \rho o ́ \delta \eta \lambda o \nu]$; but the reason for it [ $\left.\tau \dot{o} \delta \dot{\epsilon} \tau o \hat{v} \lambda o^{\prime} \gamma o v\right]$ is not easy for everyone to see';

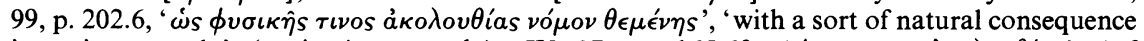

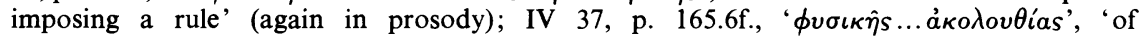
natural... consequence' (in verbal inflection). 
phenomena, just as the rationalist astronomer or doctor looks for the causes of the motions of the heavenly bodies or of sickness and disease in humans (cf. synt. III 6, pp. 271.5-272.3). ${ }^{53}$

This is no polemic against normative grammar. What is wrong here is not normativeness per se-the norm for Apollonius' time-but the absence of a general defence of it, and in particular of the special version of it-natural, rational, thorough-going ${ }^{54}$ - which Apollonius espouses. We can even put to one side the problems that arise for Apollonius (and already observed by Blank $(1982,46-9)$ ) from the need to prove certain syntactic phenomena congruous in the teeth of the evidence. (Of particular interest here, given Apollonius' dual conception of syntax, are the verb

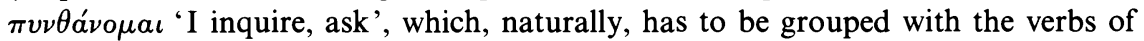
inquiry on semantic grounds, yet is irregularly constructed with the genitive and not the accusative case of the person asked (III 165, pp. 411.13-412.9), and constructions such as $\tau \rho \epsilon \epsilon \omega \sigma \epsilon$ 'I am afraid of you' and $\phi \epsilon v^{\prime} \gamma \omega \sigma \epsilon$ 'I run away from you': these

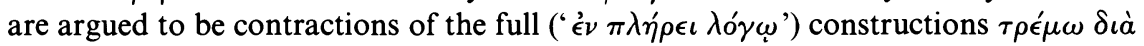
$\sigma \epsilon^{\prime}$ 'I am afraid on account of you', $\phi \epsilon v^{\prime} \gamma \omega \delta \iota \dot{\alpha} \sigma \epsilon^{\prime}$ 'I am running away on account of you', on the grounds that 'they do not imply any activity but are used with the accusative' (III 166, pp. 413.5-415.2); cf. Itkonen [1991], 215f.) What threaten his rationalist grammar are, rather, two suspicions born of his own case-studies. First, the formal deviations in words which are occasioned by the threat of ambiguity may not be rule-governed at all, but rather mere ad hoc tinkerings with a basically rational machinery. Second, and more fundamentally, that underlying rationality may itself be an illusion: we have seen cases of ambiguity, actual or possible, which appear to be analogous in all respects, but which are coped with quite differently. The resources of rationalist grammar seem to have been turned against it. When we turn to Apollonius' conception of the internal structure of grammar, ambiguity again threatens incoherence and collapse.

\section{VIII}

We have seen that some of the ambiguities discussed by Apollonius are said to be dissolved by context. Others, christened 'technical' by Lallot $(1988,40)$, are not 'real' ambiguities in the first place: no semantic difference is involved, and they come up for discussion because they permit nice grammatical distinctions to be made. For

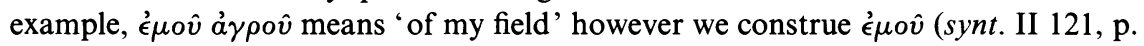
219.13ff.). Many of these are actual quotations from literary texts. Now one puzzle well worthy of investigation is how Apollonius saw his work in relation to what I shall call 'philology', the part of grammar which, roughly speaking, combines elements of textual and literary criticism- 'the noblest part' of grammar, according to the introduction to the Dionysian ars grammatica. In the very first chapter of the Syntax

${ }^{53}$ Apollonius even draws support, curiously, for his thesis of the orderliness of $\lambda o^{\prime} \gamma o$ (analogous to the orderliness of all other linguistic items) from logic. Thus, 'If Dion is walking, he is moving' is true; but (reversing the order of the constituent propositions) 'If Dion is moving, he is walking' is not (I 9, pp. 9.5-10.3). The priority in question here, however, has nothing to do with the sort of linguistic ordering found in the ordering of letters, syllables, and words (such as prepositive and postpositive articles), even words signifying a conditional proposition, the antecedent of which is logically prior to the consequent regardless of the order in which the corresponding linguistic items appear. (Apollonius displays some knowledge of Stoic logic in his use of jargon, and in the reference to the first indemonstrable (cf. Diogenes Laertius VII 80), but at p. 9.6 he refers confusedly to the whole conditional proposition, when what is needed is reference to its constituents (as Uhlig observes ad loc.).)

54 The $\sigma v \nu \epsilon^{\prime} \chi \epsilon \iota \alpha$ or 'continuity' of rational syntax (I 61, p. 52.2) is what allows it to correct any and every error of discourse - to be 'thorough-going'. 
(I 1, p. 2.1f.). Apollonius defends the study of syntax as 'absolutely essential for exegesis of the poets', and later, in the course of expounding the methodological compromise alluded to earlier, he ranges it alongside 'established Greek usage', $\dot{\eta}$ $\kappa a \tau \dot{a} \tau o ̀ \nu ~ ' E \lambda \lambda \eta \nu \iota \sigma \mu \grave{\nu} \pi_{a \rho a ́} \delta o \sigma \iota s$ : just as this is 'of enormous value, in correcting literary readings and our ordinary language too, and, further, in evaluating the imposition of names 〈on things〉 by the ancients, so, in the same way, the present inquiry into regularity will correct any error whatsoever in language' (I 60, p. 51.7-12). He is at pains, however, as this passage shows, to point out that ordinary discourse is not completely different from the literary sort; and we learn elsewhere that both contain figures, such as hyperbaton (e.g. synt. II 77, pp. 183.14-184.1), while, obviously, many of his problem cases are ordinary sentences, or at least as ordinary as the sentences grammarians ever tend to invent. ${ }^{55}$

It is the 'technical' ambiguities which must first set us wondering. Being semantically straightforward, they will generally be of little interest to the philologist with his eye mainly on correction, interpretation, and evaluation of literary texts. The fact that Apollonius makes use of them might be taken as a sign of his autonomy: whatever philologists do with the fruits of his labours, he has a subject-matter, and an authority, not derived from them. He himself at least draws a distinction between people 'understanding traditional sentential usages in a simpler way', ' $a \pi \lambda$ iov $\sigma \tau \epsilon \rho \nu \nu$ $\tau \dot{a} \pi \alpha \rho a \delta o ́ \sigma \epsilon \iota s \tau \hat{\omega} \nu \lambda o^{\prime} \gamma \omega \nu$ ', and those 'going through sentential syntax with absolute

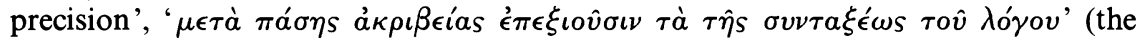
syntax in question here is that of the different grammatical cases taken by different verbs: synt. III 158, pp. 404.16-405.2). In fact, ambiguity could have been exploited to make an excellent case for the independence of technical grammar. But there is a difficulty too. A vital theoretical distinction is to be made between setting up criteria for ambiguity, on the one hand, and, on the other, setting up criteria for whether this or that bit of discourse - say, an extract from a literary text - can be understood in two or more ways. Of course, the latter process must make use of criteria for ambiguity, implicitly at least. But determining how to decide whether, say, a phrase or line of Homer, in its context, has two or more meanings is not the same as determining how to decide whether that same 'linguistic object' is ambiguous when decontextualised.

The same holds for any word or string whose ambiguity is in question. It would be missing the point to complain, say, that the old chestnut 'Flying planes can be dangerous' is uninteresting because, as a matter of fact, its tokens hardly ever have two meanings, given that its context or situation of utterance tend to make it obvious which meaning is intended. The linguist, for whatever theoretical reason, still wants to explain that and how it is ambiguous, and using whatever theoretical equipment is thought appropriate. She can then go on and examine the equally interesting and important, but quite distinct questions, how its tokens are systematically disambiguated by contexts or situations, how people recognise this, and so on. We moderns want a nice firm distinction, at least as a temporary methodological concession, between the narrowly or strictly linguistic properties of words or sentences, on the one hand, and the complex interactions between these items and the contexts or situations in which they figure, on the other.

Now Apollonius does not, I believe, have this view of the objects of his study. My point is not the obvious, but here irrelevant one, that his grammar is structured

55 Householder (1981), 5 refers to 'over a thousand' literary quotations (about 800 from Homer alone), while about 400 are 'sentences made up' by Apollonius (these figures are presumably for the Syntax alone). 
around parts of speech and their properties and behaviours. ${ }^{56}$ Nor have I forgotten that he does deal with 'technical' ambiguities, where what is at stake is correct grammatical description. For he does not, of course, limit himself to such cases: rather, as Lallot implies, he seems to treat them as quite on a par with cases where the meaning is unclear. The point to note is that he seems not to have made explicit and general the distinction, which in our eyes is vital, between the sort of ambiguous item to which his narrowly technical skills are applicable, on the one hand, and the sort on which the philologist must pass judgement, on the other. We have seen that Apollonius nowhere seems to lay down criteria for determining whether a given item is ambiguous or not, and never systematises the methods appropriate for resolving ambiguities, whether in general, or of these two different sorts, or in different sorts of discourse. And that implies he has no theoretical distinction between the sort of decontextualised, narrowly linguistic objects linguistics is conceived of as dealing with, and the more or less heavily contextualised objects, or texts, which psycholinguistics, pragmatics, macrolinguistics, or literary criticism, take as their domains today. As Ebbesen $(1988,16)$ has observed, Apollonius describes co-incident lexeis as 'losing' their ambiguity in a context (pron. 52.5); and that strongly suggests a focus on (as we should say) text rather than system.

Apollonius' handling of two Homeric problem passages will make this difference clearer. Iliad I 117 runs:

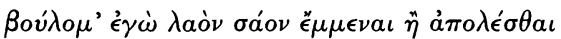

(coni. 223.10; the oddity of his treatment of this line has already been noted by Lallot [1988], 44). It can be understood as 'I want the army to be preserved or to perish' (that is, either alternative would satisfy the speaker, who is Agamemnon); or as 'I want the army to be preserved rather than to perish', depending on how the conjunction $\eta^{\prime}$ is understood. On the former interpretation, $\ddot{\eta}$ would be what

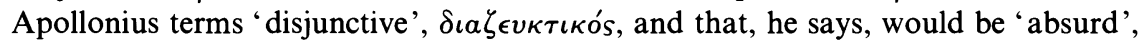

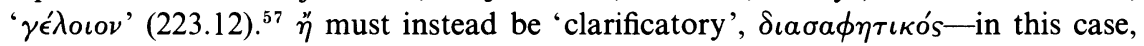
clarifying what is wanted (preservation of the army) by additionally signalling what is not (destruction of it) ${ }^{58}$ Apollonius seems to imply that it 'stands to reason', intuitively, for the commander of an army to prefer its survival to its destruction. But

${ }^{56}$ Cf. Blank (1982), 7. The overwhelming majority of Apollonius' examples are of the various parts of speech in sentences, although the examples are there to illumine the part of speech in question or to set up a problem about it, not vice versa.

57 The text at $223.8-11$ is clearly corrupt, but Apollonius' attitude is, I think, plain enough; I adopt Bekker's suggestions in $223.9,10,11$, and, less enthusiastically, Schneider's suggestion

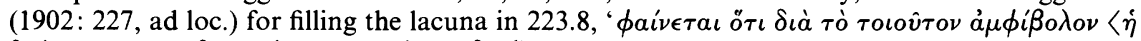
$\delta \iota a ́ \kappa \rho \iota \iota s \tau o \hat{v}\rangle \delta \iota a \sigma \alpha \phi \eta \tau \iota \kappa o \hat{v} \kappa a i \tau o \hat{v} \delta \iota a \zeta \epsilon v \kappa \tau \iota \kappa o \hat{v}$ ', 'it seems that it is because of this sort of ambiguity [sc. with regard to $\ddot{\eta}$ not in initial position] that there is a distinction between clarificatory and disjunctive $\eta^{\prime \prime}$ (on the varieties of this conjunction see $n$. 58). The text of Apollonius' handling of his next example is more problematic: see main text, below.

58 According to Apollonius, and standard contemporary logic, disjunctions are true if and only if one, and no more than one, disjunct is true (pron. 222.27f.), and they can be confused with sentences formed with the 'clarificatory' $\ddot{\eta}$, as 'paradisjunctions', those formed with the

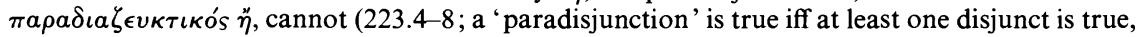
pron. 222.27-223.1). Paradisjunctive $\ddot{\eta}$ differs from clarificatory $\ddot{\eta}$ in that the latter cannot take initial position. Clarificatory $\eta^{\prime}$, however, unlike both disjunctive and paradisjunctive $\ddot{\eta}$ can

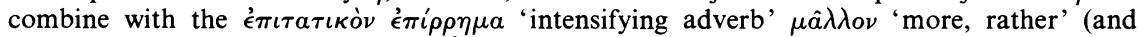
presumably also with its opposite, $\eta_{\tau} \tau$ tov 'less') (223.2-8). There is a report in the Scholia (Erbose [1969], 43.22ff.) that $\ddot{\eta}$ is here being used ' $\delta \iota \alpha \sigma \alpha \phi \eta \tau \iota \kappa \hat{\omega} s \dot{\alpha} \nu \tau i$ $\tau o \hat{v} \ddot{\eta} \pi \epsilon \rho$ ', 'by way of clarification, instead of 'rather than", citing $O d$. I 165 as a parallel: on this line, see main text, below. 
doubts about the rightness of this verdict, and then about the grounds for it, creep in immediately. First, readers both ancient and modern have not all read or chosen to read the text in this way. Porphyry, for one, is recorded as having interpreted the line as meaning that Agamemnon wanted 'the army to be saved and himself to be destroyed', with $\eta$ being a substitute for $\kappa a i^{\prime}{ }^{59} \mathrm{~A}$ modern reader might well relish the ambiguity as subtly indicative of Agamemnon's character and state of mind as he delivers this notoriously petty-minded, and potentially catastrophic, speech; and attention to Agamemnon's character, rather than to the psychology of kings and generals en masse, might also underlie Porphyry's odd interpretation. ${ }^{60}$

But this sort of distinction between ancient and modern interpretations is not yet the distinction I wish to draw. Ancient and modern literary critics can differ radically in their conception of the right way(s) to understand and assess a piece of literature, as well as in their particular interpretations and judgements, while still, typically, agreeing that what they are doing is trying to criticise a (literary) text. A modern field linguist, in contrast, would almost certainly not use such literary examples in building up a corpus of data or a description of a language, focussing instead on the 'ordinary' utterances or inscriptions of 'everyday life'; the study of stylistic features and the assessment of literary texts would be taken as belonging, respectively, to a distinct branch of linguistics and to a different discipline altogether. Recognition of this and other forms of simplification of the data-pool should accompany such methodological and meta-theoretical decisions. An integrated linguistic theory of the linguistically significant features shared by all forms of discourse, or of how language-users are able to understand both Shakespeare and the instructions on a bottle of shampoo, say, would be projected as a (distant) goal.

One path toward that goal would be the construction of accounts of the different ways in which users deal with ambiguities in different contexts, situations, and forms or styles of discourse. In the case of Iliad I 117, for example, even simple acceptance that an ambiguity may be present will not spring solely from beliefs about the grammatical properties of the Homeric dialect in general and of the conjunction $\eta$ in particular. Such acceptance also demands prior assumptions of much broader scope-assumptions about the acceptability, even inevitability, of openness or uncertainty in certain sorts of text. If, in contrast, ambiguity is regarded as a defect - the standard ancient assumption, as we have seen - the critic might well try to argue it out of existence - the standard ancient strategy. It is the strategy applied here by both Apollonius and Prophyry, who have their ideas not only about how $\ddot{\eta}$ behaves, can behave, or ought to behave, but also about strategies of reading: they have assumed that there ought to be only one meaning in the text (even if they differ

59 Scholia A, quoted by Schneider (1902), 227 ad loc., = Erbse (1969), 43.17-19, 44.1f.

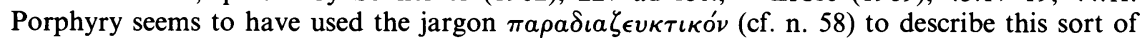
conjunction or the construction in which it appears (Erbse [1969], 43.18, 44.2). The line was

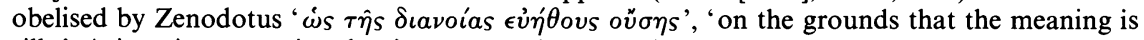
silly', Aristonicus retorting that it must not, however, be read in isolation, but together with the previous lines (Erbse [1969], 43.10-12). Kirk 1985: 66 is in broad agreement: 'It is indeed typical of the king's rather unctuous manner when he remembers his duties'. Interestingly, according to the MSS., Aristonicus explained that ' $\epsilon \dot{\nu} \tilde{\eta} \theta \epsilon \iota \gamma \dot{a} \rho \lambda^{\prime} \gamma \epsilon \tau a \iota$ ', 'it is said in character' (Erbse [1969], 43.12). Now the same Scholia as paraphrase $\tilde{\eta}$ with $\ddot{\eta} \pi \epsilon \rho$ (n. 58) add that ' $\epsilon \tau \iota \delta \dot{\epsilon} \mu \epsilon \tau \dot{\alpha}$

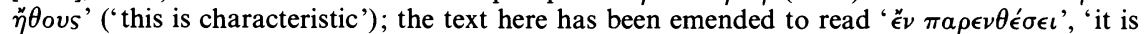
said parenthetically', but even this brief analysis of the line puts the transmitted reading in a far more attractive light.

${ }^{60}$ Porphyry's point, I take it, is that Agamemnon is declaring himself willing to preserve the army, by giving up Briseis to her father, and destroy himself (his own reputation?) in the process. 
markedly about what it is). And they so act, I take it, because they take ambiguity to be a stylistic fault, not to be attributed to Homer or any other canonical author if it can be helped.

Perhaps Porphyry's approach was more closely fitted to the demands and details of the context than was Apollonius' ostensibly straightforward, 'rational', solution to a puzzle which must have formed one of the legion of $\pi \rho \circ \beta \lambda \eta \mu \alpha \tau \alpha$ on which literary and textual critics in antiquity tried their skills. But Apollonius' answer is not thereby detached from, or elevated above, the wider context of theorising about the resolution of ambiguities. For he has surely simply assumed that this text is subject to the same considerations of rationality and consistency as any other. He has ignored the fact that this line forms part of a speech uttered by a fictional-cum-mythical character, who is displaying a decidedly mean-spirited and unattractive personality for a king; that he has just affirmed (by listing attributes, and in a way which sounds brutal even by the standards of epic) his preference for his slave Briseis over his wife Clytemnestra - an ominous declaration even to modern ears; and so on. Apollonius is thus manifestly indifferent to points of methodology and of theory which are now, justifiably, commonplace for all students of language in all in its forms: that different criteria apply to different contexts or situations in which ambiguity is suspected; that the presence of ambiguity in contextualised utterances is not guaranteed by their ambiguity as decontextualised; and that there is no such thing as the - the unique, independently specifiable - context of a contextualised utterance. That a real-life

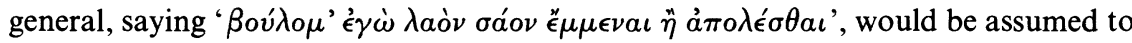
mean, in normal circumstances, 'I want my army to be preserved rather than perish' unless it were shown otherwise (evil dictators provide easy counter-examples), can only be one factor in the interpretation of Iliad I 117. Apollonius has looked at this line, not in complete isolation from the text, but rather with no more of it in view than will fix the position of the speaker. His (and all ancient) literary critical categories and standards are not to be directly compared with any of those fashionable today, and then conveniently found odd, or incoherent, or deficient in some other way. But we can now see clearly, and find grounds for criticising, the assumptions at work in his analysis and, further, in his choice of examples.

No-one would maintain that determining, let alone applying, the various criteria for ambiguity appropriate to various utterances, inscriptions, contexts, situations, and speakers, is an easy matter. Exploiting modern distinctions, we might say that Apollonius has restricted himself here to a limited pragmatic perspective: he has considered only what this (sort of speaker, characterized by rôle) might mean by this utterance. Yet he has neglected not merely certain considerations appropriate to the literary critic, whether ancient or modern, but also ones we would consider characteristic of and appropriate to the linguist. For of course the linguist would not take into account such-and-such text as spoken by so-and-so in such-and-such circumstances: the object of linguistic scrutiny is always (maximally) decontextualised. Now, even at this restricted level of analysis, the problem has still to be resolved of the extent to which semantic acceptability delimits the linguistic description(s) and meaning(s) of a (candidate) ambiguity. This, too, however, does not seem to be in Apollonius' range of vision. He has detached his Homeric problem only so far from its context: too far to see that other interpretations are possible of this particular utterance or inscription; not far enough to see that other interpretations are possible of utterances or inscriptions of this type. In brief, Apollonius has come to occupy the uneasy middle ground between philology and technical grammar, and he has done so, I submit, in part because he has failed to draw up, and has no 
apparent interest in, a list or hierarchy of the factors to be applied when assessing candidate ambiguities across the range of texts which he himself believes, and beyond a shadow of a doubt shows that he believes, fall within his competence as a technical grammarian.

I am not, please note, levelling the ridiculous accusation that Apollonius failed to strike out into the territory today's theoretial linguist would claim. This Homeric problem line will be intriguing for a modern reader because it marks the intersection of quite different sorts of linguistic properties (grammaticality as against semantic and pragmatic acceptability); of different sorts of linguistic knowledge, or even of different sorts of knowledge altogether; and we would want to use it and similar cases to get to grips with such problems. We would also observe that interpreting this line raises matters of professional importance: it highlights the institutional and methodological distinctions we draw, for purposes of our own convenience, or for deeper theoretical reasons, between different disciplines and between the internal divisions of linguistics. Now Apollonius, for his part, quotes Iliad I 117 because he is interested in the different species of a certain conjunction: no criticism to be made on this score. What makes his approach at once alien to us, and unsatisfactory in itself, is that he gives no hint that he knows or cares that quite different sorts of consideration could and should be in play in the interpretation of this line in isolation and again as part of a text. Some of these considerations will be narrowly linguistic, some broadly so, some literary critical - and one, significantly, will not be linguistic at all, the rationality which users are assumed to possess, and which is taken to act as a standard restraint on their linguistic activities. I am not demanding of Apollonius that he adopt our concerns and our conceptual schemes, disciplines, and methods: the problem is very much one of his time - the use of literary texts as objects of linguistic analysis. ${ }^{61}$

Our next example of a possible ambiguity, also involving $\eta^{\prime}$, and also, significantly, Homeric, is less easy of analysis, for the simple, regrettable, reason that the text here (as so often in the On conjunctions) is in a very poor state. Enough survives for it to be clear that Apollonius resolves this second case by again interpreting $\ddot{\eta}$ as 'clarificatory', but his reasons are not well-preserved. Odyssey I 164f. run:

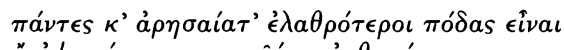

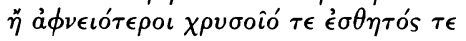

(coni. 223.13f.). The first line is straightforward: were they to see Odysseus back in Ithaca, Penelope's suitors 'would all pray to be fleeter of foot'. The second threatens an ambiguity, between 'or 〈to be > rich in gold and clothing' and 'rather than 〈to be > rich in gold and clothing'. Someone-not necessarily Apollonius himself, the text is not in good enough shape for this to be clear-argues that $\eta$ is an ordinary disjunctive in this context: the suitors would pray either to be fast enough to run away from Odysseus, or rich enough to persuade him - presumably, not to kill them (again, the text gives out) (223.15-18). Apollonius disagrees: 'it is clear that $\langle\check{\eta}\rangle$ is clarificatory here. For they will rather pray to be swift 〈than〉 very rich' $(223.18-20){ }^{62}$ Two

${ }^{61}$ Two quite different sorts of consideration are brought in to determine the interpretation of another problem line, Iliad XVIII 460, where two grammatical rules are invoked, one governing the position of prepositive pronouns, the other stating that no verb is construable with two nominative cases; and the immediate context is also appealed to (synt. I 152f., pp. 122.7-124.8; cf. Lallot [1988], 44-6).

${ }^{62}$ Reading ' $\delta\langle\tau \iota \delta \iota \alpha \sigma \alpha \phi \eta\rangle \tau \iota \kappa o ́ s ~ \dot{\epsilon} \sigma \tau \iota$ ' with Schneider at 223.19: clearly right, because Apollonius goes on to paraphrase 1l. 164-5 as 'they will rather [ $\mu \hat{a} \lambda \lambda o \nu]$ pray to be swift ...', and he has explicitly associated $\mu \hat{a} \lambda \lambda o \nu$ with clarificatory $\hat{\eta}$ at 223.4 . 
considerations seem to have been advanced in support. The first would be narrowly grammatical: in I $164 \kappa \epsilon$ ' should be taken as $\pi \alpha \rho a \pi \lambda \eta \rho \omega \mu \alpha \tau \iota \kappa^{\prime}$, 'expletive, complementary' (223.18; cf. $247.23 \mathrm{ff}$.) - that is, as equivalent to $\mu \hat{a} \lambda \lambda o \nu$ and not to $\alpha{ }^{\prime} \nu$, helping to convey the notion of choice implicit in the optative 'á $\rho \eta \sigma a i a \tau o '$. Unfortunately, it is not absolutely clear that this was the point made by Apollonius himself; again, the text lets us down. ${ }^{63}$

The second consideration in play seems to have been broadly philological. Coni. 223.22 is a quotation of Odyssey XXII 61:

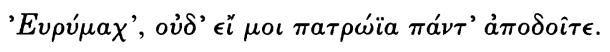

This line forms part of Odysseus' famous first confrontation with Penelope's suitors, as he speaks from the threshold of the hall. ${ }^{64}$ What is the reason for its appearance here? In the original context, Eurymachus has just promised Odysseus compensation for all the expenses he may have incurred by their long residence in his home (ll. 55-9); and now Odysseus is replying that 'even if you were to give me in return everything you have inherited from your fathers' he would not stay his hand from vengeance. The implication is that Telemachus' words all the way back in Book I (quoted at 223.13f.) are to be read as looking forward to the moment of his father's return, and to the disdain for mere material recompense which Odysseus will then express.

If this was Apollonius' approach, it represents a far more plausible piece of philology than the question-begging interpretation of Iliad I 117 (and perhaps more convincing, for us, than the other argument he seems to have advanced here, that based on the rôle of $\kappa \epsilon)$. But, whatever our assessment of the relative worth of these two considerations, we should not lose sight of the fact that Apollonius is again putting on display the resources of technical grammar in helping to solve Homeric $\pi \rho \circ \beta \lambda \eta^{\prime} \mu \alpha \tau \alpha{ }^{65}$ And he again does so without considering, at least explicitly and as a matter of strategy, whether he is here advancing two qualitatively different considerations, and, if so, of what sorts they are; nor is there any hint, here or elsewhere, that he asked whether different considerations again might apply to other types of discourse, or how to decide what weight to assign to each when the need arises.

${ }^{63}$ Egenolff's restoration of 223.15-21, followed by Schneider in his commentary (1902: $227 \mathrm{f}$. ad 223.15), makes this point Apollonius' own; but it is puzzling that the suggestion first appears

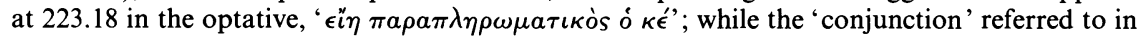
223.20 may be $\eta$ itself, not $\kappa \dot{\epsilon}$, as Egenolff would have it. Unfortunately, Apollonius' only extant discussion of $a ̈ \nu$, which he regards as a ('potential', $\delta v \nu \eta \tau \iota \kappa o ́ s) ~ c o n j u n c t i o n$, is restricted to its use in (what we call) unreal conditionals (synt. III 21, p. 286.1ff.); the further treatment promised at 288.3f., in the context of the syntax of conjunctions, is lost from Book IV.

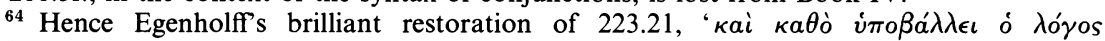

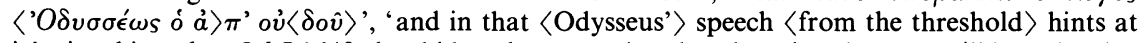
it'-i.e., hints that $O d$. I 164 f. should be taken as saying that the suitors' prayer will be to be able to run away from Odysseus.

${ }_{65}$ The Anecdota Oxeniensa (I. A. Cramer [ed.], Oxford, 1835-37) I 189.26, reported by Schneider (1902, 227, ad coni. 223.15), shares Apollonius' interpretation and criticises the

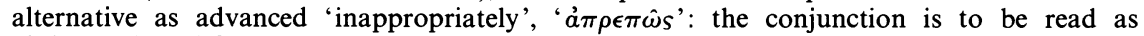

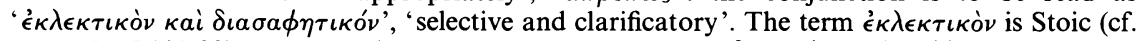
Anec. Ox. I 189.22). It presumably described the proposition ' $\delta \iota a \sigma a \phi o v \hat{\nu} \tau \hat{o} \mu \hat{a} \lambda \lambda \nu_{\nu}$ ', 'indicating what is rather more 〈the case than not〉' and possibly also that 'indicating what is rather not

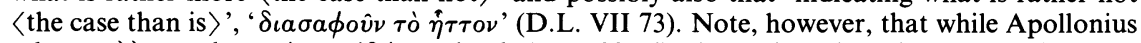
takes $\mu \hat{a} \lambda \lambda o \nu$ to be an intensifying adverb (coni. 223.4), the Stoics labelled it 'the conjunction indicating what is more 〈the case〉' (D.L. VII 73). 
It is worth noting a case-not of ambiguity this time-which suggests that Apollonius' professional interest in literary texts can at least confirm him in poor grammatical judgement. At pron. 9.17ff. Apollonius argues that every pronoun is demonstrative or anaphoric, and that both types refer to definite individuals, objections to this second claim notwithstanding (10.18-26). The first such objection, which alone concerns us here, exploits Odyssey VI 158:

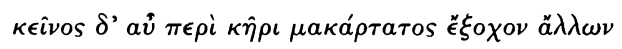

which is part of Odysseus' first speech to Nausicaa: 'But that man again is blessed in his heart beyond all others', the man, Odysseus means (1. 159), 'who will lead you to

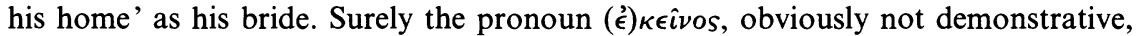
does not refer to a definite individual anaphorically either? Not so, replies Apollonius: 'The anaphoric reference is, however, understood as being to an individual who is certainly [ $\left.\pi \alpha \nu^{\prime} \tau \omega s\right]$ going to exist, which he [sc. Odysseus], using these auspicious words, announces in advance'. Tradition (with which I take it Apollonius was familiar) had it that Nausicaa married Odysseus' own son, Telemachus. ${ }^{66}$ But that union-whatever justification, or value, invoking Odysseus' unwitting (?) foresight may have from a literary standpoint-does nothing to alter the grammatical fact that

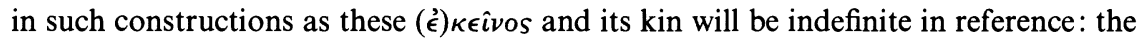
line in question is equivalent to "whoever marries Nausicaa will be blessed above all men', regardless of whether the speaker has some one, definite bridegroom in mind. That extra piece of information is no part of the construction or, for that matter, of a user's knowledge of Greek.

So it looks very much as though Apollonius has used Homer to help prop up a shaky piece of grammar. (The same line is used to much the same purpose at synt. I 44, p. 39.13f. $)^{67}$ An irrelevant literary-cum-mythical context has provided 'evidence' that an apparent exception falls under the rule being defended-a rule Apollonius would surely have had to modify had he considered comparable generalisations lacking such special contexts. He does seem to have different views about analogous constructions with definite articles. ${ }^{68}$

\footnotetext{
66 Another tradition, of course (invented by Robert Graves), has it that Nausicaa wrote the Odyssey.

${ }^{67}$ Householder's translation here $(1981,34)$ is, I think, misleading, in failing to convey

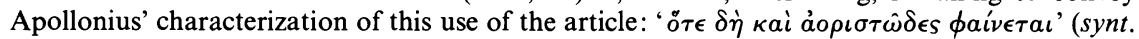
I 44, p. 39.10) means 'when indeed it even appears indefinite' not 'when the phrase is used indefinitely (i.e. generically)'. (The same misleading translation, 'generic', is used at I 111, p. 94.14 [p. 64], 114, p. 96.2 [p. 65]: see n. 68.) Apollonius seems anxious to remind us that articles behave like pronouns in such constructions, where the indefiniteness of reference is (taken as)

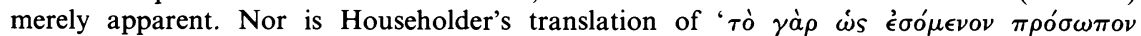

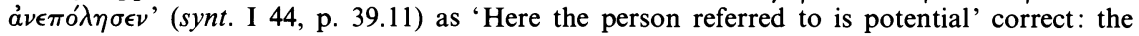

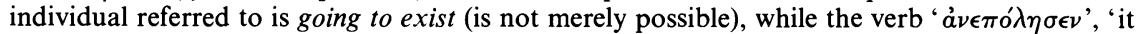
has recalled', must indicate that prior recognition of that individual is assumed. Uhlig's running paraphrase of I 44 acknowledges this in a parenthetical assertion, with no parallel in the Greek, that reference is to a thing '... [quam tamen mente iam concepit et is qui loquitur et alter ad quem loquitur, quocirca hic quoque dicere licet repeti id, quod iam antea cognitum est]', '... [which, however, both speaker and addressee have thought of, so that there too it is acceptable to say that what was thought of previously is being mentioned again]'.

68 Apollonius' views on 'indefinite' constructions containing definite articles and appellatives (= nouns and adjectives) or participles are not entirely straightforward, however. At synt. I 111, p. 94.11f., he apparently admits them (and notes that the Stoics appealed to them to justify calling 'indefinite' what we, and Apollonius, call 'definite' articles (94.12f.); cf. e.g. pron. 5.13f.).
} 
It is surely significant that the cases where this is most apparent are taken from literary texts: central to Apollonius' enterprise is his ability to provide solutions to textual-cum-literary problems, and Homer must prove amenable to rationalist explanations. Despite all the differences between literary and non-literary discourse-Apollonius himself refers to 'poetic licence', $a ̊ \delta \iota \iota \pi$ $39.16,40.2$, 93.4)-discourse in its entirety must come within his area of competence. And hand-in-hand with that claim to authority there comes, at least in the case of ambiguity, the failure to separate, in a general and explicit way, what is from what is not narrowly linguistic, the objects of grammar from the objects of philology. Whatever is needed to solve a problem - grammatical rules, the immediate or a wider context, semantic or logical considerations - is used as needed and without justification. If an ancient parallel is wanted. I offer Cicero's handling of ambiguity as a source of legal dispute - where, again, what matters is the result, not how you get there (inv. II 116f.). ${ }^{69}$

$\mathbf{X}$

I may have overstated my case. Perhaps Apollonius had a perfectly good practical understanding of the difference between contexts and contextualised items, and was able, case by case, to exploit literary passages as illustrations of whatever limited points he wished to make, regardless of the other points which could be made about them from other perspectives. For, of course, ancient grammatical practice in general took literary texts to be wholly appropriate objects of study — whether at Apollonius' sophisticated level, or as models for schoolboys - in a way that is quite irreconcilable with modern linguistic practice or theory. And this whole paper might seem to have missed the simple point that ancient grammarians tended to make literary texts at once paradigmatic and abnormal, models of discourse whose peculiar properties - the grammarian's field of competence - none the less prevented them being legitimate models of actual discourse, except within certain, narrowly prescribed, limits as to times, places, users, and audiences. As we have seen, Apollonius himself speaks of poetic usages being 'returned to clarity, and ordinary parlance', 'á $\nu a ́ \gamma \epsilon \tau \alpha \iota$

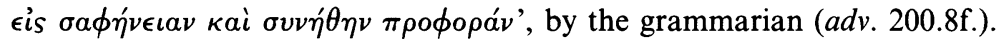

So I will make my last stand. Recall that Apollonius does not offer a general classification of ambiguity types, or even so much as a definition, the wealth of material available to him in both these areas notwithstanding. A case might be made that Apollonius, not being interested in ambiguity per se, has need only of as much conceptual and terminological precision and consistency as serves his purpose, and that it is wholly inappropriate to expect of him distinctions we may think important

He himself characterises them as selecting one from a plurality (synt. I 111,94.10f.), e.g. 'Let the boy who has eaten go to bed'; and at I 114, p. 96.1-3 the imperative mood 'turns out to be the reason for the construction of article and participle, e.g. 'let the man having killed a tyrant $[\dot{o}$ $\tau \nu \rho a \nu \nu o \kappa \tau o \nu \eta ́ \sigma a s] ~ b e ~ h o n o u r e d ', ~ b e i n g ~ i n d e f i n i t e ~ i n ~ c o n c e p t i o n ~[a i \tau i ́ a ~ \gamma i ́ v \epsilon \tau a \iota ~ \tau o v ~ a ́ o \rho \iota \sigma \tau \omega \delta \hat{~} s$

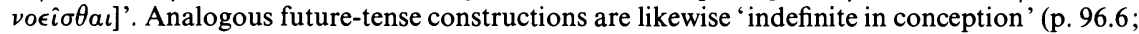

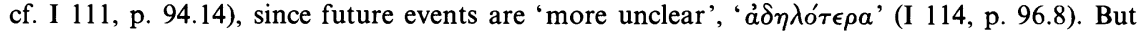
an analogous present- or past-tense construction is instead labelled 'more anaphoric',

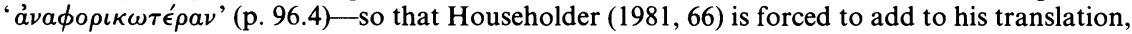
in parentheses, that such constructions are 'normally' anaphoric, and observe that 'the present can also mean "any tyrannicide is honoured, in general"'. At II 32, p. 149.9-15, in fact, such generalisations as 'The 〈man〉 walking is in motion', $\delta \pi \epsilon \rho \iota \pi \alpha \tau \hat{\omega} \nu \kappa \iota \nu \epsilon \hat{\imath} \tau a \iota$, are described as involving an 'indefinite transformation' of definite articles; Householder $(1981,97)$ remarks that here Apollonius 'fails to see that this is merely the generic article which also occurs with nouns and adjectives'.

${ }^{69}$ On this aspect of ancient approaches to ambiguity, see further Atherton (1993), 496ff. 
(such as that between ambiguity of reference and ambiguity of sense), especially given the generally quite different approach to classification of ambiguity in antiquity. But this will not do. Looseness and vagueness may be excused in this or that case, but the crucial question remains unanswered: what, exactly, explains Apollonius' lack of interest in ambiguity per se? In order to want to define or classify ambiguity he would first have had to recognise the rôle or rôles which it was playing in his grammatical explanations. He would not have dwelt on the nature of ambiguity, or on its range of possible species, or on the criteria which determine its presence or absence in a given text, without a motive for doing so. And that motive, I propose, could only have been the intention to codify all the factors which determine the properties of language, both its basic regularity and the rule-governed departures from it. A complex hierarchy of those factors would follow naturally, with inflectional or syntactic regularity overruled by semantic considerations in these cases but not in those. But Apollonius seems never to have taken such a long hard look at the structure he was building as a whole; and he never, accordingly, recognized what a mixed-what an ambiguous-blessing ambiguity would prove for him. ${ }^{70}$

New College, Oxford

CATHERINE ATHERTON

\section{Bibliography: Ancient}

Apollonius Dyscolus

de adverbiis (adv.), de coniunctionibus (coni.), de pronominibus (pron.), in: Grammatici Graeci (G.G.) II i 1, R. Schneider (ed.), (Leipzig, 1878; repr. Hildesheim, 1965; cited by page and line numbers); de syntaxi (synt.), G. Uhlig (ed.), in: G.G. II ii (Leipzig, 1910; repr. Hildesheim, 1965 ; cited by book and section, and by page and line numbers; e.g. 'III 27, p. 292.17f.' refers to section 27 of Book III, at p. 292, 1l. 17f. of Uhlig's edition). (Also de pronomine liber, I. Bekker (ed.), (Berlin, 1813); de constructione orationis libri quatuor, I. Bekker (ed.), (Berlin, 1817); de pronominibus, P. Maas (ed.), Kleine Texte für Vorlesungen und Uebrigen 82 (Bonn, 1911).)

Dionysius Thrax (D.T.)

Ars grammatica, in: G. G. I i, G. Uhlig (ed.), (Leipzig, 1883; cited by page and line numbers).

Scholia on Dionysius Thrax' Ars grammatica (D.T. Sch.)

In: G. G. I iii, A. Hilgard (ed.), (Leipzig, 1901; cited by page and line numbers).

Grammatici Latini (G.L.), H. Keil (ed.), (Leipzig, 1857-1880; VII vols. + supplement; repr. Hildesheim, 1961, 1981; cited by vol., page, and line numbers).

Rhetores Graeci, L. Spengel (ed.), (Sp.) (Leipzig, 1853-6, III vols.; repr. Frankfurt-am-Main, 1966 ; cited by vol., page, and line numbers).

Erbse, H., (ed.) (1969) Scholia Graeca in Homeri Iliadem (Scholia Vetera), vol. I (Berlin).

Bibliography: Modern

Anderson, S. R. (1976) 'On the notion of subject in ergative language', in Subject and Topic, C. N. Li (ed.), (New York), 3-23.

Atherton, C. (1993) The Stoics on Ambiguity (Cambridge).

Blank, D. (1982) Ancient Philosophy and Grammar. The Syntax of Apollonius Dyscolus. Chico, California: Scholars Press. (American Philological Association: American Classical Studies, $10)$.

Butts, R. E. (1986) The 'Progymnasmata' of Theon. A new text with translation and commentary (Diss., Claremont).

Chao, Y. R. (1959/60) 'Ambiguity in Chinese', in: Studia Serica Bernhard Karlgren dedicata: Sinological Studies dedicated to B. Karlgren on his 70th birthday, S. Egard, E. Glahn (eds.), (Copenhagen), 1-13.

Chomsky, N. (1967) 'The formal nature of language', in: The Biological Foundations of Language, E. H. Lenneberg (ed.), (New York), 71-100.

${ }^{70}$ I would like to thank Geoffrey Horrocks and the participants in the Colloquium on Dionysius Thrax organised under the auspices of the Henry Sweet Society and held at Sidney Sussex College, Cambridge, in July 1993, for their comments on the first draft of this paper; and Geoffrey Horrocks, Peter Matthews and Robert Wardy for comments on a later version. 
Comrie, B. (1978) 'Ergativity', in: Syntactic Typology: Studies in the phenomenology of language, W. P. Lehmann (ed.), (Austin, TX), 329-94.

Comrie, B. (1981) Language Universals and Linguistic Typology (Oxford).

Comrie, B. (1988) 'Coreference and conjunction reduction in grammar and discourse', in Hawkins 1988a, 186-208.

Desbordes, F. (1988) 'Homonymie et synonymie d'après les textes théoriques latins', in Rosier 1988, 51-102.

Ebbesen, S. (1988) 'Les grecs et l'ambiguïté', in Rosier 1988, 15-32.

Frede, M. (1978) 'Principles of Stoic grammar', in: The Stoics, J. Rist (ed.), (Berkeley, LA and London), 27-75.

Greenberg, J. H., Osgood, C., Jenkins, J., (1966) 'Memorandum concerning language universals', introduction to Universals of Language: Report of a conference held at Dobbs Ferry, NY, April 13-15, 1961, J. H. Greenberg (ed.), (Cambridge, MA, 2nd edn.; 1st edn., 1963).

Greenberg, J. H., (ed.) (1978) Universals of Human Language (Stanford; 4 vols.).

Hawkins, J. A., (ed.) (1988a) Explaining Language Universals (Oxford, 1988).

Hawkins, J. A. (1988b) 'Explaining language universals', in Hawkins 1988a, 3-28.

Hirst, G. (1987) Semantic Interpretation and the Resolution of Ambiguity, (Cambridge).

Hockett, C. F. (1954) 'Two models of grammatical description', Word 10, 210-34 (repr. in Readings in Linguistics, M. Joos (ed.), [Washington, 1957]).

Householder, F. (1981) The 'Syntax' of Apollonius Dyscolus. Translated, and with Commentary. Amsterdam: John Benjamins. (Amsterdam Studies in the Theory and History of Linguistic Science, Series III: Studies in the History of Linguistics, 23).

Itkonen, I. (1991) Universal History of Linguistics. India, China, Arabia, Europe (Amsterdam/ Philadelphia: Amsterdam Studies in the Theory and History of Linguistic Science, Series III. Studies in the History of the Language Sciences, 65.

Kaimio, J. (1979) The Romans and the Greek Language (Commentationes Humanarum Litterarum LXXIV) (Helsinki).

Keenan, E. L. (1988) 'On semantics and binding theory', in Hawkins 1988a, 105-44.

Kirk, G. S. (1985) The Iliad: a commentary. Vol. I (Cambridge).

Kooij, J. G. (1971) Ambiguity in Natural Language (North-Holland Linguistic Series III). (Amsterdam and London).

Lallot, J. (1988) 'Apollonius Dyscole et l'ambiguïté linguistique: problèmes et solutions', in Rosier 1988, 33-49.

Lana, I. (1951) Quintiliano, Il 'Sublime', e gli 'Esercizi Preparatori' di Elio Teone (Turin).

Lloyd, A. C. (1978) 'Definite propositions and the concept of reference', in: Les Stö̈ciens et leur Logique, J. Brunschwig (ed.), (Paris), 285-95.

Mallinson, G., Blake, B. J. (1981) Language Typology (Amsterdam).

Matthews, P. H. (1993) Grammatical Theory in the United States from Bloomfield to Chomsky (Cambridge).

Payne, J. R. (1990) 'Language universals and language types', in: An Encyclopaedia of Language, N. E. Collinge (ed.), (London and New York), 281-330.

Rosier, I., (ed.) (1988) L'Ambiguïté: Cinq études linguistiques (Pr. Univ. de Lille)

Schneider, R. (1902) Commentarium criticum et exegeticum in Apollonii Scripta Minora, G.G. II i 2 (Leipzig; repr. Hildesheim 1967).

Siebenborn, E. (1976) Die Lehre von der Sprachrichtigkeit und ihren Kriterien, Studien zur antiken normativen Grammatik (Amsterdam).

Sluiter, I. (1990) Ancient Grammar in Context: Contributions to the Study of Ancient Linguistic Thought (Amsterdam).

Wells, R. S. (1947) 'Immediate constituents', Language 23, 81-117. 